\title{
DEPENDING ON THE ANGLE: \\ PERSPECTIVES OF CONFLICT AND WORKPLACE CLIMATE
}

\author{
A Thesis \\ Presented to the Faculty of the Graduate School \\ of Cornell University \\ In Partial Fulfillment of the Requirements for the Degree of \\ Master of Science
}

By

Kelly Irene Pike

January 2009 
(C) 2009 Kelly Irene Pike 


\begin{abstract}
In this thesis, a case study of ten nursing homes is used to identify different styles of management and different approaches to dealing with conflict. Much of the literature on conflict focuses on determining which types are negative and which types are positive. What I illustrate, however, is that the same types of workplace issues exist in different organizations, yet do not necessarily yield similar outcomes in terms of organizational climate. Closely examining this relationship will put us in a more informed position to forecast the likelihood of successful organizational change - in this case, the implementation of electronic medical records (EMRs). This thesis leans on previous research in the area of organizational culture, climate, and perspectives on conflict. Specifically, the research question I examine is how organizations with the same types of conflict can experience vastly different workplace climates. What I found was that different perspectives of conflict, not necessarily the conflicts themselves, were what shaped either positive or negative workplace outcomes. This finding contradicts past research that suggests it is merely the existence of certain types of conflict that determine workplace outcomes. Instead, I propose that different perspectives of conflict, as reflected in different types of management style, are what have primary influence in shaping workplace climate.
\end{abstract}




\section{BIOGRAPHICAL SKETCH}

Kelly completed her undergraduate degree at Cornell's ILR School in 2003. Before returning to Cornell, she interned as a strategic researcher at the Food and Allied Service Trades in Washington, D.C. and at the American Federation of Teachers headquarters. In October 2006, Kelly began work as a research assistant at the Institute on Conflict Resolution (ICR) in the ILR School and entered the MS/PhD program in August 2007, majoring in Conflict Resolution. Kelly is originally from Ottawa, Canada and she continues to do research at the ICR in addition to her academic studies. 


\section{ACKNOWLEDGMENTS}

I would like to thank my advisor, Professor David Lipsky, for his ongoing support, and generosity in extending my involvement with the Institute on Conflict Resolution. His interest in my personal development, research and career goals has enabled me to contribute to both causes at once and learn an incredible amount along the way. I also want to acknowledge my colleague, Ariel Avgar, for the mentorship, collaboration, and consistent feedback. Some of his previous research is touched on in this thesis, as part of the foundation for my own research in the field. I am also grateful to Professor Bill Sonnenstuhl for providing his expertise on organizational culture and offering guidance throughout the stages of my master's thesis. 


\section{TABLE OF CONTENTS}

Biographical Sketch $\quad$ iii

Acknowledgements

Table of Contents $\quad$ v

List of Figures vi

List of Tables vii

Preface viii

Chapter One: Introduction 1

Chapter Two: Literature Review 3

Organizational Culture and Organizational Climate 3

$\begin{array}{lr}\text { Perspectives of Conflict } & 12\end{array}$

$\begin{array}{ll}\text { Sources of Conflict in Healthcare } & 15\end{array}$

$\begin{array}{ll}\text { Chapter Three: Methods } & 21\end{array}$

The Nursing Homes: Location, Selection, and Size 21

$\begin{array}{ll}\text { The Interviews: Structure and Intentions } & 23\end{array}$

Identifying Types of Nursing Homes $\quad 25$

Chapter Four: Going Into the Homes 28

Approaches to Workplace Issues in Different Types of Homes 28

$\begin{array}{ll}\text { Chapter Five: Discussion } & 62\end{array}$

Perspective on Conflict Reflected in Management Style and Climate $\quad 62$

$\begin{array}{ll}\text { Implications for Different Types of Homes } & 67\end{array}$

$\begin{array}{ll}\text { Conclusion } & 68\end{array}$

$\begin{array}{ll}\text { Appendix A } & 70\end{array}$

$\begin{array}{ll}\text { References } & 74\end{array}$ 


\section{LIST OF TABLES}

Table 1 Comparison of Organizational Climate Dimensions 9

Table 2 The Nursing Homes: Bed Size, Number of Residents, and County 22

Table 3 Approaches to Workplace Issues in Different Types of Homes 60

Table 4 Perspective on Conflict Reflected in Management Style and Climate 62 


\section{LIST OF ABBREVIATIONS}

Admin: Administrator

Asst Admin: Assistant Administrator

Asst DNS: Assistant Director of Nursing Services

Auth: Authoritarian

CNA: Certified Nursing Assistant

DNS: Director of Nursing Services

EMRs: Electronic Medical Records

LPN: Licensed Practical Nurse

Part: Participatory

Phys: Physician

Prog: Progressive

RN: Registered Nurse

Temp: Temporary Employee 


\section{PREFACE}

In 2006, the Quality Care Oversight Committee (QCOC) administered a grant to New York State to screen and select seventeen nursing homes in the greater New York City area as part of a pilot project to adopt electronic medical records (EMRs). These homes were provided with the resources to implement the EMRs and, as part of this initiative, Cornell was asked to conduct an evaluation of the impact that the EMRs would have on employment relations. Throughout the first year of the project, our small research team conducted an extensive review of the literature, put together a survey instrument in which 1,200 nursing home employees participated, and have had the opportunity to visit ten of the seventeen nursing homes to interview administrators, nurses, union representatives and other front-line staff. This research was conducted in the early stages of EMR-implementation, either just before or as it was being put in place. Follow-up interviews will be conducted at each of the homes one year after 'going live' with the EMRs, at which time any changes due to the new technology will be more easily observable. This thesis takes on a portion of this larger project, focusing on the relationship between conflict and climate, as influenced by management perspective on conflict. 


\section{CHAPTER 1: Introduction}

This study discusses common sources of organizational conflict, in particular the workplace issues most frequently alluded to by both administrators and front-line employees in nursing homes, and the variety of ways in which these conflicts are viewed based on different types of management style. By looking at how different styles of management organizational climate, we generate hypotheses about the factors influencing this process.

Drawing on Joanne Martin's “Three-Perspective Theory of Culture,” this thesis takes an integration approach to the study of organizational culture (Martin 2002). That is, culture is viewed as a common set of values that people share - the social glue that holds a group together (Smircich 1983). This is not to exclude contributions to the research on the differentiation approach, which views organizations as being full of conflicts of interests, recognizing that differences exist between subgroups (i.e., labor and management) but focusing more on what enables or prevents them from relating to one another. We do indeed take these inconsistencies into account and recognize that people and organizations are more complex than what is shown on the surface. Keeping an awareness of these nuances, the aim of this thesis is to identify different types of management style in nursing homes by looking at similarities and differences across a series of organizational characteristics.

While conducting interviews in ten nursing homes, it was apparent that several common sources of conflict existed in each of the homes but not every home viewed conflict in the same way. Some viewed conflict as a negative, detrimental to the organization. Others viewed conflict as a positive, as an opportunity to learn and continually improve the organization. From these observations, three types of nursing homes have been identified, delineated in this thesis by their particular styles of management. I hypothesize that different types of homes will view conflict 
differently, which will in turn have different implications for affecting any kind of organizational change. This thesis fleshes out the interview feedback to more clearly illustrate this pattern and will ultimately serve as a springboard for an analysis of the role that management style and perspectives of conflict play in the successful implementation of electronic medical records in nursing homes. 


\section{CHAPTER 2: Literature Review}

In this chapter I review the literature on both organizational culture and organizational climate, including a variety of definitions, instruments for their measurement, and how the two have been differentiated from each other. This is supplemented with a brief review of the literature on the role of management in shaping organizational climate, and how climate can affect workplace outcomes. I also review the literature that traces different perspectives of conflict back to the theoretical contributions of ancient philosophers, up through the activities of modernday organizations. Lastly, I review the literature on workplace conflict, both in general and within the nursing home context. There are several common sources of conflict across organizations but there are a few in particular that are more prominent in nursing homes. These are discussed in more detail towards the end of this chapter.

\section{Organizational Culture}

When visiting the nursing homes, I formed ideas about what was happening, based on observations and conversations at all levels of the organizational hierarchy. However, given that we each view things differently according to our own experiences, my interpretations were subjective, and my lens for studying organizational culture admittedly biased. In Joanne Martin’s book, Organizational Culture: Mapping the Terrain, she discusses three different lenses, or perspectives, from which cultural studies can be examined: integration, differentiation, and fragmentation (Martin, 2002).

Integration studies assume that culture is "what people share - the social glue that holds people together - whether that glue be values, a shared sense of purpose, deep tacit assumptions, or simply habits of behavior" (Martin, 108). Differentiation studies, on the other hand, look at organizations as being full of conflicts of interests. Whereas one tradition within the differentiation perspective emphasizes relatively 
harmonious relationships among subcultures (i.e., Trice \& Beyer, 1991/92), others emphasize some type of disconnect between subcultures (Brunsson, 1985; Mumby, 1988; Rosen, 1985). The important point is that differences are recognized and it isn't so much about the values that people share as it is the ability (or not) of subcultures to relate to each other.

As an example, Martin alludes to a study done by Barley (1986) in which he looked at how the introduction of computerized tomography scanners into hospitals altered the relationship between the technicians and radiologists. The technicians had greater skill in operating the new machines, which incidentally left the radiologists feeling like their former high status had been undermined (Martin, 102). This "critical theory perspective" stresses inconsistencies and conflicts between subcultures at different levels of an organizational hierarchy (Martin, 103) and advocates giving voice "to the perceptions and opinions of those who are less powerful or marginalized" (Martin, 11). When Riley (1983) studied two large consulting firms, formal conversations centered on themes of teamwork and cooperation whereas informal conversations revealed layers of aggression and competition among professionals (Martin, 101). A study by Brunsson (1986) is another example of a differentiation study focused on cultural manifestations with inconsistent interpretations (Martin, 101).

While integration and differentiation studies focus on clarity - clearly shared values or clear divides between subgroups - fragmentation studies focus on ambiguity; that it is to say that culture "includes multiple, contradictory meanings that are simultaneously true and false, paradoxes, ironies, and irreconcilable tensions" (Martin, 110). This perspective is reflected in how Martin perceives social science theory, the purpose of which is "not to comfort managers with promises of relatively 
easy solutions but to capture and perhaps even construct organizational experiences, in all their discomforting complexity, conflict, ambiguity, and flux" (Martin, 9).

Martin argues that all three of these perspectives should be used when studying a culture: what she calls the three-perspective theory of culture. This is illustrated in her definition of organizational culture, which draws attention to the various ways in which culture manifests itself within an organization but more importantly stresses the need to look for something deeper. Beyond surface level details, she proclaims, cultural observers seek "an in-depth understanding of the patterns of meanings that link these manifestations together, sometimes in harmony, sometimes in bitter conflicts between groups, and sometimes in webs of ambiguity, paradox, and contradiction" (Martin, 3). Although the focus of this study is on identifying common values shared among groups and individuals within organizations, the important role that differences play in these homes is equally emphasized. In a way, the clashes that continually surface among groups might say just as much about culture as the values they share.

Many definitions of organizational culture have emerged within the literature over the past few decades, summarized in Table 3.1 of Martin's book (p.57-58). Culture can be viewed as a "set of important understandings (often unstated) that members of a community share in common" (Sathe, 1985, p.6) or as "the articulation of communication rules" (Schall, 1983, p.3). Additionally, Schein wrote that, "to really understand a culture and to ascertain more completely the group's values and overt behavior, it is imperative to delve into the underlying assumptions, which are typically unconscious but which actually determine how group members perceive, think, and feel" (Schein, 1985, p.3). This study supports the belief that communication rules - how work gets done, how decisions are made, how leadership is structured - lend themselves to understanding organizational culture and argues that 
managerial style is a key predictor of this. This is also in alignment with Meyerson's definition that "shared orientations and purposes accommodate different beliefs and incommensurable technologies...imply different solutions... and have multiple meanings" (Meyerson, 1991, p.131), reinforcing that we cannot look only at what is clear and shared, and that we need to look at individuals as well as groups and subgroups.

Kunda, for example, did a study in 1992 in which he described how employees enacted a corporate ritual in a very conforming way, according to what they thought they were supposed to do, which was based on their idea of the ritual's meaning (Kunda, 1992). These rituals included a variety of structured face-to-face gatherings: speeches, presentations, meetings, lectures, parties, training workshops, and so forth. Each event was an occasion for the participants to speak as agents for the corporate interest by using familiar symbols, such as stylized forms of expression and company slogans, to articulate and exemplify what members in good standing are to think, feel, and do (Kunda: 92). Their behavior during breaks in these rituals, however, was more self-questioning and almost somewhat embarrassed, capturing a layer of ambiguity that interestingly seems more common than an attempt to find commonality itself (Kunda, 1992).

I consider managerial style to be a key component of organizational culture, but certainly not its equivalent. Although its effect on employment and labor relations is an important feature of culture, equating one alone to the other would be an oversimplified attempt at making sense of something much more complex. Management style, alone, does not account for the inconsistencies we find among groups of nurses (independent of administrative implications), nor does it necessarily reflect the views of all workers at different levels of employment. And it would be difficult to argue that the employees' deeply held values, beliefs and norms lay within management's 
hold. I do, however, believe that management style is largely responsible for informing organizational structure, decision-making, and freedom to take risks - all of which play a key role in shaping workplace climate. In this respect, I use management style as an indicator of 'types' of nursing homes and consider management's perspective on conflict to be reflected in a variety of organizational processes.

\section{Organizational Climate}

A good example of how management style influences workplace climate is Van Maanen's 1991 report on the tensions that existed between first-line supervisors and ride operators at Disneyland (Van Maanen, 1991). Martin provides an excerpt from page 61 of Van Maanen's study that describes how supervisors would hide in order to secretly watch whether employees were running rides on time or doing anything they shouldn't be. Supervisors were regarded by line operators as "sneaks and tricksters, out to get them and representative of the dark side of park life" (Martin, 189). In another study, by Smircich and Morgan (1982), the president and staff of a large insurance company were described as having conflicting interpretations of a new management initiative which the president stressed would get rid of the backlog of work but the workers saw as management's inability to confront the real issues (Smircich and Morgan, 1982). For the staff, the reality was that the organization was not a team and instead "a poorly managed group characterized by narrow self-interest, and non-cooperation at anything but a surface level" (Martin, 189).

Previous research demonstrates a relationship between climate and workplace outcomes. Davidson, for example, looked at the effect of organizational climate on service quality in hotels (Davidson 2003), while Carr et al. looked at individual-level outcomes such as job performance, psychological well-being, and withdrawal through their impact on organizational commitment and job satisfaction (Carr et al. 2003). In this thesis, the focus is on how management style affects climate, as influenced by 
different perspectives of conflict. First, it is important to distinguish between what is meant by culture, what is meant by climate, and how they are measured.

\section{The Culture/Climate Debate}

Up until the late 1980s, the distinction between organizational culture and organizational climate was quite clear. Culture researchers looked at the evolution of social systems over time (Mohr, 1982; Pettigrew, 1979; Rohlen, 1974; Schein, 1985; Van Maanen, 1979), the importance of underlying assumptions (Schein, 1985; Kunda, 1992), individual meaning (Geertz, 1973; Pondy et al, 1983) and the insider's point of view of the organization. Climate researchers looked at the impact of organizational systems on groups and individuals (Ekvall, 1987; Joyce and Slocum, 1984), members' perceptions of organizational life (Guion, 1973; Jones and James, 1974), along with the categorization of these practices and perceptions.

As the literature grew, definitions of 'culture' and 'climate' began to overlap and the two - which began as separate and distinct topics for study - experienced more liberal interchange. Quantitative culture research in the early 1990s started to look a lot like early research on organizational climate (Denison and Mishra, 1995) and it wasn't always clear as to which constructs of culture and climate referred to various aspects of organizational life. In other words, this research was running the risk of "reducing culture to just another variable in existing models of organizational performance" (Siehl and Martin, 1990: 274).

Emerging from this increasing blurring of the lines was an attempt by various scholars in the mid-1990s to delineate the boundaries of these concepts and more clearly articulate their meaning in the workplace (Denison, 1996; Verbeke et al., 1998; Wallace et al., 1999). This was done by going back to the early literature to once again establish culture and climate more clearly within their own theoretical frameworks, and through a variety of empirical studies that ultimately produced a 
commonly agreed upon set of instruments for measuring both culture (Hofstede, 1990; O'Reilly and Chatman, 1992) and climate (Davidson et al., 2001; Ryder and Southey, 1990; Jones and James, 1979). See, for example, Table 1 below.

Table 1 Comparison of organizational climate dimensions

\begin{tabular}{|c|c|c|}
\hline Davidson et al. (2001) & Jones and James (1979) & $\begin{array}{l}\text { Ryder and Southey } \\
\text { (1990) }\end{array}$ \\
\hline $\begin{array}{l}\text { Leadership, facilitation } \\
\text { and support }\end{array}$ & $\begin{array}{l}\text { Leadership, facilitation } \\
\text { and support }\end{array}$ & $\begin{array}{l}\text { Leadership, facilitation } \\
\text { and support }\end{array}$ \\
\hline $\begin{array}{l}\text { Professional and } \\
\text { organizational esprit }\end{array}$ & $\begin{array}{l}\text { Professional and } \\
\text { organizational esprit }\end{array}$ & \\
\hline Conflict and ambiguity & Conflict and ambiguity & \\
\hline $\begin{array}{l}\text { Regulations, organization } \\
\text { and pressure }\end{array}$ & & Conflict and pressure \\
\hline $\begin{array}{l}\text { Job variety, challenge and } \\
\text { autonomy }\end{array}$ & $\begin{array}{l}\text { Job challenge, } \\
\text { importance and variety }\end{array}$ & $\begin{array}{l}\text { Job variety, challenge and } \\
\text { esprit }\end{array}$ \\
\hline $\begin{array}{l}\text { Work group cooperation, } \\
\text { friendliness and warmth }\end{array}$ & $\begin{array}{l}\text { Work group cooperation, } \\
\text { friendliness and warmth }\end{array}$ & $\begin{array}{l}\text { Work group cooperation, } \\
\text { friendliness and warmth }\end{array}$ \\
\hline Job standards & Job standards & $\begin{array}{l}\text { Organization planning } \\
\text { openness }\end{array}$ \\
\hline
\end{tabular}

(Davidson 2003)

Culture is rooted in social reconstruction theory, which emphasizes the evolution of social context, and refers to deeply rooted traditions, values, beliefs and sense-of-self (Denison, 1996; Sopow, 2007). Borrowed from the social sciences, social reconstruction theory is grounded in symbolic interaction and social construction perspectives developed by Mead (1934) and Berger and Luckmann (1966). It draws a close connection between the symbolic and material world; the simultaneous creation of meaning and social structure (see for example, Van Maanen, 1979; Kunda, 1992).

Climate, rooted in Lewinian theory, pays more credence to the impact of social context, or, the "here and now" (Sopow, 2006). Also borrowed from the social sciences, this theory derives from the early field work of Kurt Lewin (1951), and the 
strength of this perspective is in conceptualizing a particular type of social process involving the influence of an established context on organizational members who are in subordinate positions of power (Denison, 1996). Lewinian theory would be useful, for example, in studies that look at the impact of a system on its members. Research by Chatman, O'Reilly, and Van Maanen are a few examples that illustrate the contrast between these perspectives (Chatman, 1991; O'Reilly et al, 1991; Van Maanen, 1973, 1975).

Such great effort was put towards emphasizing the differences between these two topics that the literature soon cycled back to argue that it would be nearly impossible to separate the two from each other, stressing the importance of looking at common threads amidst their differing theoretical foundations.

In a 1996 article entitled What is the difference between organizational culture and organizational climate? A native's point of view on a decade of paradigm wars, culture and climate were broken down by their differences in research perspectives and their areas of convergence in the literature, along with a comparison of selected dimensions used by both culture and climate researchers (Denison, 1996: 625, 627, 631). In this way, the author demonstrated that culture and climate are two different perspectives, not two different phenomena of which one should be studied at the exclusion of the other.

In a more recent study, one author provided a simple way of understanding the fluidity of the relationship between culture and climate by comparing 'organizational personalities' to those of human personalities (Sopow, 2006). He suggested that both are shaped by hereditary and developmental factors - the culture - which in turn influence the design of organizational system structures that shape daily behavior - the climate. Similarly, we as human beings are not defined only by our current 
environments, but where we came from, what we're made up of, how we adapt to change, learn, grow, and the ways in which we help to form subsequent generations.

While there are indeed differences in the theoretical traditions of culture and climate, it is commonly agreed upon in the current literature that they are not completely distinct from each other. This is especially evident in the interest that both have in examining and understanding the social context of organizational life (Ashkanasy et al, 2000; Cooper et al, 2001).

In 2001, John Stolte and Gary Fine published an article that used an organizational metaphor called "sociological miniaturism" to examine large-scale social issues by looking at small-scale social institutions (Stolte et al, 2001). This approach to studying organizations placed primary importance on the texture of everyday life and posited three fundamental claims about the nature of reality: transcendence, representation, and generalizability (Stolte : p.388). Transcendence is to say that what is observed on the interpersonal level, for example, can also be observed on the institutional or interorganizational level (Harrington and Fine, 2000). This model also assumes that the behavior of individuals can be treated as representing larger social entities (representation) and that situations can be meaningfully generalized (Stolte: 389). This symbolic interactionist perspective is representative of the theoretical foundations of organizational culture, but it simultaneously considers the happenings of everyday life - a common approach taken in organizational climate research.

In an earlier article by Fine, Negotiated Orders and Organizational Cultures, he suggested that both negotiated order and organizational culture focus on the actor's perspective on life in an organization, and that they are complementary but rarely brought together. Negotiated order, he argued, is created by the collective behavior of groups in an attempt to redefine their social situation collectively and determine the 
relevance of a particular ideology to the organization (Fine, 1984, p. 252). This concept is in line with definitions of organizational culture as a core set of values and beliefs held by members within an organization. Prior to this work, Riley demonstrated that organizations do not have a single, unified culture, but rather a system of subcultures and a set of complementary perspectives (Riley, 1983). Fine then extended by suggesting that one's position in the organization will determine how one will see the issues to be negotiated and the cultural traditions that underlie the negotiation (p.253). Even though he is writing about organizational culture, he suggests that differing perceptions of processes and procedures held by an organization's members will form both individual and collective responses, which in turn shape organizational climate.

This thesis demonstrates how management's perspective on conflict creates a particular type of style that directly influences employee perceptions of workplace climate. First, a discussion of different perspectives on conflict is warranted.

\section{Perspectives on Conflict}

Organizations in any industry have to deal with conflict, but not every organization views or addresses conflict in the same way. Some see it as an absolute negative, with the goal of preventing and eliminating it at all costs. This perspective, which has been referred to as the classical view of organizational conflict, is shared by theorists such as Fayol (1916/1949), Taylor (1911) and Weber (1929/1947), and implicitly assumes that conflict is detrimental to organizational efficiency and therefore should be minimized in organizations (Rahim 2001, p. 8). Robbins (1974) describes this perspective as the philosophy of the classicists or traditionalists, which is based on the assumption that conflict is detrimental to an organization and should be reduced or eliminated (Rahim, 2001, p. 11). 
Others think that conflict is inevitable - part of the behavioralists' philosophy - and, rather than focusing on how to get rid of it, try to come up with systems for managing it effectively. Mary Parker Follet (1926/1940) noted the value of constructive conflict in an organization in saying, "we can often measure our progress by watching the nature of our conflicts" (Follett, 1926/1940, p. 35). She strongly advocated the need for a problem-solving method for managing organizational conflict and believed that other methods of handling conflict, such as suppression, avoidance, dominance, and compromise, were ineffective in dealing with conflict. Similarly, Whyte (1967) reiterated that conflicts are an inevitable part of organizational life and stressed the importance of building conflict resolution procedures into the design of an organization, (Whyte, 1967, p. 25).

There are still others who view conflict as a positive, essential for sparking communication and innovation, which promotes efficiency at both an individual and organizational level. Conflict becomes an instrument of social change and influence, rather than a symptom of a breakdown in social relationships. Kerr (1964) was a leading figure in the application of this theory to the study of conflict in organizations. Additionally, Miles (1980) took a functional approach to conflict, viewing it in terms of how its presence inspired such things as feedback, coalition formation, growth and innovation. He said that these functions and dysfunctions revealed something about both the centrality of conflict in organizational life and the complexity associated with its management, making it absolutely essential to understand the context in which organizational conflict occurs and the variety of techniques available for use in its management (Miles, 1980, p. 129). Rather than strive to eliminate conflict, this approach recognizes the necessity of conflict in facilitating positive growth in the workplace. 
More recently, Karen Jehn has written on types of conflict, identifying which ones produce negative outcomes and which one produces positive outcomes (Jehn, 2001). She makes a distinction between task conflict and relationship conflict and discusses how high or low levels of each type of conflict affect workplace outcomes in different ways. She claims that task conflicts tend to be positive as they spark debates that can lead to organizational improvement. Relationship conflicts, on the other hand, tend to be negative as they deal with heated interpersonal issues that often make people feel angry or frustrated in the workplace. She also suggests that different conflict norms - having different levels of openness in the process of addressing conflict - have various implications for the organization. Sometimes having open and honest communication facilitates the effective resolution of conflict, primarily if it has to do with tasks. Other times, this same process can increase anxiety and frustration, proving counterproductive - as is the case with relationship conflicts (Jehn, 1995; Murnighan and Conlin, 1991).

Rather than attempt to identify positive and negative types of conflict, this study identifies common sources of conflict in nursing homes and then discusses how management's perspective on conflict influences employee perceptions of climate. This is illustrated in a later chapter through interview feedback received from (1) nursing home administrators regarding their particular styles of management and (2) front-line employees regarding workplace relationships, and how work gets done, in their homes. In this section, we draw from the literature on common sources of workplace conflict in health care and how they apply in the nursing home context. 


\section{Sources of Conflict in Health Care}

\section{Breakdowns in Communication}

Much is changing in the health care industry, with rising costs, burnt out nurses, and rapid technological advances. These factors take a heavy toll on professional relationships and communication which in turn compromise a healthy working environment and quality of patient care. Breakdowns in communication are one of the key themes that emerge in the literature as a source of conflict in health care. Breakdowns in communication in any setting, whether it be an organization, a sports team or even within our own families, seldom lead to positive outcomes. In the healthcare industry, breakdowns in communication and teamwork have a direct effect on the quality of patient care. Studies have found that the culture among healthcare professionals is one of conflict avoidance and last minute power-based negotiation, yielding what is perceived as a passive-aggressive approach to conflict, which damages working relationships and increases the likelihood of communication breakdowns that lead to treatment errors. Additionally, differences among professional subgroups as to definitions of conflict and cooperation, and perceptions of collaboration and teamwork, make coordination of care difficult and resolution of conflicts less likely (Werner Institute website).

Some institutions are led by administrators who value team-based learning and resident-centered care. Others exude a sense of chaos and poor quality care, deriving from more hierarchical leadership structuring and meager communication skills at best. These intimidating behaviors, failure to address concerns among peers and rigidly structured hierarchies continue to affect the ability of healthcare organizations to provide safe care and result in an increased mistrust of the health system by consumers (Werner Institute website). 
However, the communication factor itself is not what determines how happy the staff is. Rather, it is the climate within which the communication takes place. Whether it is a reward climate or a laissez-faire climate is management's decision and will either enhance or hinder the effect of communication on work place relationships (Anderson 2002). An article on team learning and new technology implementation in hospitals highlights the importance of leadership and team work in accepting new technologies. The psychological safety, or trust, that people feel can be more important than the benefits of the technology itself. No matter how good it is, if people are not comfortable with it, it's not going to be successful. The study reported that successful implementers used enrollment to motivate the team, and designed preparatory practice sessions and early trials to create psychological safety and encourage new behaviors, promoting shared meaning and process improvement through reflective practices (Edmondson 2001). Here, the collective learning process is illuminated. Both upper management and an interdisciplinary team need to be included in the implementation process. By educating all stakeholders, trust is built and anxiety is reduced (DeLaHunt) among the various individuals, groups and subgroups of the organization.

\section{Relationships with Physicians}

Historically, there has always been conflict involving physicians; sources of these traditional types of conflict have been rooted in things such as quality of care, nursing staff quality, medical errors, or communication issues. (Burns, 1993). Physicians are a unique class of healthcare workers because they are often independent contractors for the healthcare facility. The independent status of most physicians - and the autonomy which accompanies this status - feeds into the difficulties that healthcare organizations have in dealing with conflict among organizational hierarchies. As Joanne Martin writes, "if conflict is to be successfully 
reduced, hierarchical relationships need to be minimized or temporarily suspended" (Martin, p.69).

Physicians perceive their professional culture as being founded on close-knit social networks. In the medical community, they rely on their professional peers as a primary source of information and interaction (Ford, 2006). Aligned with this concept of social networks, physicians may not be receptive to change if they are concerned that it will lead to a loss of control over patient interactions, disruptions in their workflow, or subsequent changes in management and leadership that may in turn create further conflict (Winkelman, 2005). For example, with the implementation of electronic medical records in nursing homes, physicians may demonstrate local resistance to this perceived disruption in their traditional workflow by not utilizing the technology (Weiss 2002).

Not only do the aforementioned factors influence facilities in the disciplining of physicians should the need arise, they also affect the organization's ability to get physicians "on board" or in conformance with organizational goals or policies. In an interview by a former colleague, the CEO of Carolinas Hospital System stated that "physicians are more apt to listen to physicians, especially if they are in the same specialty; for this reason it is important to have physicians whom you can depend on to champion causes and goals to the rest of the medical community" (Smith, 2007).

\section{Turnover}

One of the reasons behind staffing problems is that employees do not always know the residents very well because they are not involved in their care or they are not resident-centered in their care-giving approaches (Klitch, 2000). In other words, they aren't interacting with them, communicating with them, or trying to get their feedback as far as specific requests they may have to make life more comfortable in the nursing home. Employee turnover also contributes to this decline in resident care, for similar 
reasons of not being able to develop relationships with the residents and care for them in the ways they need (Adendorff, 2003).

Not only does turnover negatively impact the staff, but it has a direct effect on residents in that quality staff leave and therefore aren't able to develop the kind of relationships with residents that create a positive atmosphere within which they can live. One important predictor of turnover rates is the proportion of resources allocated to administrative functions and roles (Anderson, 1997). As mentioned in Complexity Science and the Dynamics of Climate and Communication, predictors of turnover have more to do with management processes than they do with facility structure or individual psychosocial measures of staff well-being (Anderson, 1997). Fewer people end up doing the work of many, again leading to an increase in stress and higher potential for accidents, presenting a threat to staff relationships, nursing home reputation, and the quality of resident care.

\section{Layoffs}

There will always be some workers who are concerned that any organizational change or new initiative will ultimately lead to layoffs. The threat of layoffs, perceived or real, may lead to heightened tensions and animosity in the workplace. Not all employees receive physicians' salaries and may work double shifts just to support a family (Martinez-Motta, 2004). If workers are concerned about job security, they will fight to save their jobs and not be as worried about patient care, opening the door to higher levels of stress, increased numbers of mistakes, and an overall decrease in employee morale.

\section{Morale}

Staff cliques have led to a number of issues within nursing homes, most typically among groups of nurses. Cliques are self-selected groups of employees who speak the same language, share the same attitudes, and tend to exclude those who do 
neither (Greet 1996). Some administrators have tried to dissipate the damaging effects of cliques by putting a few staff from each group on the same committees or by counseling employees one-on-one. But history runs deep and there is an entrenched lack of understanding between aides and LPNs that continues to lead to anger, conflict, and poor interpersonal skill development (Lesco-Long, 2000). Given that there is already conflict and violence in nursing homes, mainly deriving from this lack of understanding between the workers, any change that threatens a decrease in necessary communication may further hinder these relationships, possibly increasing the amount of conflict and violence that takes place.

\section{Trust}

A key retention factor for employees is positive relationships with their direct managers. They are happiest when they feel like they are cared about as people, given feedback on their performance, provided with encouragement, and included in decision making (Hollinger-Smith, 2003). One article reports that, in nursing homes where morale problems exist because of staff cliques, poor working conditions and poor management attitudes, trying to effect changes of any kind is going to be far from smooth (Greet, 1996). For employees to embrace change of any kind, managers need to embrace a new set of values by focusing on building these positive relationships (Deutschman, 2005).

\section{Job Satisfaction}

HR recommendations for increased employee job satisfaction always have to do with job-related policies or structures in the organization so that there is some kind of procedural change. However, job satisfaction is more dependent on what is perceived as valued, appropriate and justifiable behavior in the workplace (LescoeLong, 2000). When the focus is strictly on changing organizational policies without changing these human perceptions, employees possibly interpret the meaning of their 
work in a different way than HR personnel do. This can lead to misunderstanding and, as cited in the Lescoe-Long article, the main source of job dissatisfaction is that frontline employees don't understand each other. This is further intensified by organizational bureaucracy and lack of personal satisfaction.

In this chapter, I have drawn on literature in the areas of organizational culture, climate, and conflict, in order to create context for understanding what factors influence the relationships between them. In the remainder of this thesis, I focus in particular on the link between management style and organizational climate, and the role that managerial perspective on conflict has in shaping this relationship. By looking at a number of workplace issues in nursing homes, and management's attitude towards dealing with conflict, we will gain a deeper appreciation of the beliefs and values held within the organization, as well as an understanding of employees' perception of climate. Using this as a complement to the literature on organizational climate and workplace outcomes, we will be in a better position to understand how different types of homes are able to respond to organizational change. 


\section{CHAPTER 3: Methods}

\section{The Nursing Homes: Location, Selection, and Size}

All of the nursing homes we visited were located in the New York City (NYC) region, and part of a 140-home bargaining unit represented by SEIU 1199. The pilot project to adopt EMRs in nursing homes grew out of a collective bargaining agreement in which a Quality of Care Oversight Committee (QCOC) had been established. In 2006, the QCOC applied for and received the grant from the State and then went through a screening process to determine which homes would receive the money for EMRs. All nursing homes were invited to apply for the grant and, based on the given criteria, seventeen homes were chosen. Information dissemination and training began the following summer and, by August 2007, a number of the homes had already begun to 'go live' with EMR implementation; this was when our first wave of interviews began.

For budgetary reasons, we were able to include only ten of the seventeen nursing homes in our study. These ten homes represent four boroughs and two counties in the NYC region. The table below breaks down the number of beds, number of residents, and occupancy rate in each home, as found on Www.ucomparehealthcare.com, a search engine for information on hospitals and nursing homes, last updated on 02/08/08. 
Table 2 The Nursing Homes: Bed Size, Number of Residents, and County

\begin{tabular}{|c|c|c|c|c|}
\hline Home & \# Beds & \# Residents & $\begin{array}{c}\text { Occupancy } \\
\text { Rate }\end{array}$ & County/Borough \\
\hline 1 & 520 & 401 & $77 \%$ & Orange County \\
\hline 2 & 320 & 303 & $95 \%$ & Manhattan \\
\hline 3 & 270 & 267 & $99 \%$ & Brooklyn \\
\hline 4 & 240 & 236 & $98 \%$ & Bronx \\
\hline 5 & 240 & 174 & $73 \%$ & Brooklyn \\
\hline 6 & 200 & 191 & $96 \%$ & Bronx \\
\hline 7 & 200 & 189 & $95 \%$ & Bronx \\
\hline 8 & 200 & 176 & $88 \%$ & Queens \\
\hline 9 & 183 & 177 & $97 \%$ & Queens \\
\hline 10 & 180 & 167 & $93 \%$ & Nassau County \\
\hline
\end{tabular}

The average number of beds in these homes was 255. Excluding one home that had 520 beds, the average was 226 . The three lowest occupancy rates were $73 \%$, $77 \%$, and $88 \%$. All of the others ranged from $93-99 \%$. Of the ten homes, seven rated below the state average ( 84 minutes) on number of minutes per day that all types of nurses are on duty to tend to each resident. Of those seven, six were below the national average (78 minutes). For details, see www.ucomparehealthcare.com.

The homes were located in a cross-section of socioeconomically diverse neighborhoods and, assuming that this has an impact on each home's access to resources, one might expect there to be a disparity in terms of capacity for organizational change. Our semi-structured interview process allowed for questions that addressed whether or not administrators would have done more or less if they were in a different socioeconomic situation. This is addressed in this thesis through feedback to questions regarding motivation for adopting the new technology and whether or not administrators would have done so without the grant. While some stated that they would not have participated in the project without the grant, others proclaimed that they would have done it regardless - if not at that exact time, then 
some time in the near future. Interestingly, some of these homes in the latter category were economically on par with the homes who said it would be too expensive to implement EMRs without outside help.

In the homes that were financially and geographically better off, we asked administrators and directors of nursing services if they felt their socioeconomic status influenced their choice to participate in the project. One home stated that they would have participated anyway because they felt this was the next necessary step in improving resident care and the working lives of their employees. Another home, although not as quick to answer, suggested that they, too, would have likely gone ahead with it. The inconsistency among these answers raised some skepticism as to whether or not socioeconomic issues played a primary role in management's choice to adopt the technology. In other words, socioeconomic status did not immediately appear to hinder or improve capacity for organizational change, at least not on the point of access to resources. Where it did seem to be reflected was in the attitudes of employees regarding their preferences for a certain type of management style, their desire for change, and what they felt they were capable of. Management decisionmaking had less to do with socioeconomic drivers and more to do with their values and beliefs about how to run an organization, and the perceptions held by the employees as to the type of climate created by this process. In this paper I argue that these different managerial styles grow out of different perspectives on conflict.

\section{The Interviews: Structure and Intentions}

Going into the homes, our goal was to get a sense of what life was like in each nursing home before the technology was implemented, so that we could go back a year later and evaluate how employment and labor relations had been affected by the technology. Knowing that we would be dealing with a variety of employees (labor and management, those with supervisory roles and those without), we prepared three 
separate sets of interview questions: one for administrators, one for front-line employees, and one for union representatives (see Appendix A for the complete listing). These questions allowed us to get a sense of what the managerial style was like in each home and what the climate was like for employment and labor relations. While we went into these homes with a set list of questions, the structure of the interviews was informal. Our intention was to get to each of these questions but we were also flexible as to how much we used them to guide the conversation.

On the one hand, some of the people we spoke with were shy and somewhat hesitant. In these instances, it was helpful to have a list of interview questions to keep the conversation flowing and alleviate some of the pressure they may have felt. On the other hand, some of the people we spoke with were extremely outgoing and opinionated. Using the questions simply as a peripheral guide allowed the conversation to develop according to the unique perspective of the interviewee - for example, what they perceived to be the main issues at the home or what the biggest concerns were for them personally. In addition to the feedback we got in response to specific questions, such as how work was done at each home, these tangential conversations were particularly interesting as some employees expressed vastly different outlooks from other employees within the same home. We asked questions pertaining to a variety of organizational characteristics, listened to the individual stories and experiences that employees were willing to share, and were constantly observing the behavior of employees both within their own subgroups and across other groups. Interviewing at all levels, from administrators to nurses to CNAs and union representatives, several patterns started to emerge.

First, we found that a few common sources of conflict, or workplace issues, were most frequently alluded to throughout our interviews and in our observations while touring the inside of each nursing home. Second, while these issues existed in 
each of the homes, not every home had the same type of workplace climate. In this section, we extend our understanding of conflict and organizational climate by identifying these sources of conflict, discussing their role in the nursing home context, how they can be viewed differently, and how they can be broken down in to additional subsets of conflict.

\section{Identifying Types of Nursing Homes}

Combining direct interview feedback with our impressions of the more subtle workplace nuances, we began to notice both similarities and differences that either bridged or set homes apart from one another. In one home, where management had an authoritative style, it appeared that decisions were made to gain tighter control of the staff. In particular with the implementation of electronic medical records, the goal was to heighten surveillance and discipline. In another home, which was more progressive in terms of its aim to improve its organization by staying abreast of technology, a monitoring theme still emerged but with more focus on the learning aspect. Decisions were made to improve overall efficiency of the organization, while at the same time improving the quality and skill set of their staff. In the third home, management was more participative with their staff, attempting to empower them through involvement in decision-making and teamwork on the floor. Each of these homes had the ultimate goal of achieving higher quality of care, but each had its own unique style and approach to doing so.

As we continued to visit the rest of the homes, we noticed that each one tended to display managerial characteristics similar to at least one of the initial three homes we had visited, demonstrating a potential pattern. Based on our impressions and on feedback obtained in the first round of interviews, we categorized this pattern into three types - authoritarian, progressive, and participatory. These are described below, briefly, and then further elaborated on in chapter 4. I do not intend to conclude that 
there must be only three specific types of nursing homes, nor that there are only three particular types of management style. My goal is rather to provide an interpretation of the observations we collected throughout our interviews, and to use this in forming a model for understanding how perspectives on conflict relate to organizational climate.

\section{Authoritarian Homes}

Each of these homes had the common feature of having administrators who put control at the center of how they ran their organizations. This came out particularly in what they had to say about their decision-making processes and their relationships with the staff, union members and officials. The managerial style was paternalistic and the tactics for discipline were punitive. It seemed the approach to dealing with workplace issues was to minimize, if not entirely get rid of, anything that could potentially be problematic. Given these observations, I propose the following:

Proposition 1: Administrators with an authoritarian management style have a negative perspective on conflict.

\section{Progressive Homes}

Consistent across each of these homes was a desire on the part of management to improve efficiency in the organization by staying abreast of changes that would enhance the skill development of their staff. In this case, that change happened to be the implementation of EMRs. Management understood that their workers would make mistakes, but viewed this as a learning opportunity and chance for them to improve. In these homes, administrators were eager about the anticipated benefits of the technology but also realistic about the bumps in the road ahead of them.

Proposition 2: Administrators with a progressive management style have a neutral perspective on conflict. 


\section{Participatory Homes}

In each of the participatory homes, key themes that emerged were employee empowerment through active involvement, and a high degree of both teamwork and communication. Mistakes and errors were viewed as an opportunity for both individual learning and organizational improvement, and all employees were regarded with dignity and respect.

Proposition 3: Administrators with a participatory management style have a positive perspective on conflict.

To illustrate these different perspectives, and subsequently how they influence organizational climate, the following section discusses how similar workplace issues are viewed by management in authoritarian, progressive and participatory homes. As a disclaimer, a good portion of my research in nursing homes has been conducted through the lens of anticipating technological change and its effect on organizational structure and workplace relationships. I draw on the previously discussed literature, as well as interviews with administrators and front-line employees regarding their perceptions of how the implementation of EMRs may add to or alleviate existing conflict in nursing homes. While a good portion of the feedback is in response to the hesitations about, and anticipated benefits of, the new technology, valuable insights are gleaned from statements regarding how people feel about their roles in the workplace, what limitations they have, what opportunities exist for advancement, and how they relate to their peers and managers.

The words "Authoritarian", "Progressive", and "Participatory" have been abbreviated to "Auth", "Prog", and "Part", respectively. The numbers represent different homes within those categories. A complete list of abbreviations is available at the front-end of this thesis. 


\section{CHAPTER 4 - Going into the Homes}

\section{1) Organizational Hierarchies}

\section{Authoritarian Homes}

In the first home we visited, the structure was clearly top-down, with a need for control coming through in how the administrator spoke about his staff and residents with a heavy paternalistic tone. His expressions focused around knowing what was best for everyone, making decisions without input from others, and having impressive means for supervising both staff and residents. He took pride in the fact that he had over fifty video cameras placed throughout the nursing home and that he knew what was going on at all times because he would come in during the night to check up on people and have his staff report everything to him directly.

When we arrived at the home, the meeting room had been set up with a long table and there was a group of six staff members, two certified nursing assistants (CNA), two registered nurses (RN), a union rep, and the director of nursing services (DNS). We met as an entire group, something we hadn't anticipated, and immediately felt the tension in the room. The CNAs were quiet, sitting back with their arms folded across their chests, looking concerned and perhaps a bit disgruntled. The RNs seemed bitter, talking about the extra work they had to do to make up for what other staff should be doing and then having to face the consequences for something that wasn't their responsibility. After discussing a few questions about employment relations at the home and talking about their impressions of the technology, the RNs and DNS left the room. Almost instantaneously, the CNAs broke out:

Auth1, CNA: "They're the ones that are the problem. They do nothing and expect us to do everything. We have too many residents to look after and, if we miss one thing, they won't help out with it and we end up hearing about it. They're so lazy and think they're above everyone else." 
The disciplinary style here was punitive and measures for monitoring employees were implemented with the specific goal of identifying wrong-doers and punishing them accordingly. This created a tense atmosphere of fear and hesitation where workers were afraid to do anything outside of their job description in case they were to make a mistake and get in trouble. Decision-making was more authoritative than it was collaborative and employment relations were poor, with a clear divide between those with supervisory roles and those without; sometimes a divide existed even within those subgroups. There were issues of accountability: each person seemed to be out for his or herself, doing only what was required and quickly pointing the finger at someone else when anything went wrong.

In the second authoritarian type home we visited, there was again a clear need for control from a top level but, in this particular home, it came from the DNS. Even though the administrator had been at the nursing home for thirty years, she had a somewhat hands-off approach to decision-making in the organization, deferring authority to the DNS.

Auth2, Administrator: "I don't want to micro manage. If anything, it might change the way the nursing director does her job. The CEO made the decision for EMR. Everyone has to by 2012 anyway... We have to do it, so might as well."

We also spoke to a physician at this nursing home who reiterated that there were external factors influencing the decision to adopt EMRs:

Auth2, Physician: "Money is the big player. This home probably wouldn't have done this without money from the State.

In contrast to the complacency of the administrator at this home, and in support of her claim that the DNS would be more likely to be the one checking up on the staff, the following statement by the DNS indicated that her primary purpose for supporting 
the adoption of EMRs was indeed for the benefit of tighter surveillance and monitoring:

Auth2, DNS: "I want to know if and when residents are getting their meds. If there's a problem, I want to know which nurses are involved. There's going to be better quality of life because people can be kept in check. If it's not good for them, let them be afraid. The residents' lives are in our hands. Now I will be having more eyes to see what is going on."

This provided some insight in to the punitive disciplinary style and the state of employment relations at the nursing home, as tactics for discipline stem partially from levels of cooperation between management and front-line stuff. That is, if management perceives its staff as being lazy, uncooperative or difficult to manage, it will likely implement more punitive styles of discipline (i.e., warnings, terminations, looking for mistakes the employees are making) rather than learning styles (i.e., inservice, re-education, looking at how the organization itself can improve).

Interestingly enough, while the DNS intended to use the technology as a supervision tool and mechanism for managing more closely, she was at the same time also very keen to be moving forward with it.

Auth2, DNS: "When the real problem comes, you have to see how it will go. We have to go forward with the technology. We don't want to sit in one corner. If you are afraid for the accident, you will never drive."

Still, even her enthusiasm found a way to overshadow the true feelings that others may have had about the technology, or any opportunity they may have had to express their opinions. At one point during our meeting, one of the kitchen staff came in to bring us some milk for our coffee and the DNS asked her if she was excited about the technology. When she hesitated (the technology really wasn't going to impact her job), the DNS pressed on: 
Auth2, DNS: "You're excited about it right? It's going to be great, right?" To which the staff member relented:

Auth2, Kitchen staff: "Yes, it's going to be really good."

Proposition la: In authoritarian homes, administrators might choose to capitalize on a vertical structure of organizational hierarchy, using their authority in top-down decision-making and punitive disciplinary styles. This can lead to an atmosphere of fear and hostility, leaving employees feeling uninformed and mistrusting.

\section{Progressive Homes}

In the second type of home we visited, the disciplinary style came from the perspective of improving overall learning. If employees weren't doing something correctly, rather than punish them for it, the goal was to offer additional training or an in-service - something to improve their skill set and to make them better at doing their job. Decision-making in the organization was done on a collaborative level.

Employees were more informed because they were overall more involved in the every day processes of the workplace. They knew about changes that were occurring and felt like they had an opportunity to express their opinions. They were clear on their responsibilities and generally aware of their environment.

We visited the first progressive home the day after visiting the first authoritarian home. The contrast was astounding. In this home, our first impressions were a sense of genuine collaboration, compared with the lack of accountability and tension that was so present in the air at the authoritarian home.

Prog1, Area VP: "The administrator is what makes this place; she's collective, gives dignity and respect to workers." 
Prog1, Contract Administrator: "[Prog1] is doing this project for growth, to elevate into the future, combine past and future. [The administrator] is very energetic."

Administrators in progressive homes also viewed the technology as a monitoring tool but, rather than use this as a measure for discipline, they recognized the potential for learning that is involved with the experience. The administrator at the first progressive home we visited noted that efficiency and accountability are two of the benefits she anticipated would result from the technology. She was also realistic in pointing out that using the technology as a disciplinary tactic could undermine the role of supervisory leadership on the floor, which could have counterintuitive effects on the provision of quality care. She was supported by the Area VP in this belief, who stressed a need to make sure the employees felt safe in undergoing the technological change.

Prog1, Administrator: "Once I know there's a problem, I wouldn't disregard leaders or use technology to replace management; the software is a tool; it doesn't replace good skills, good judgment and common sense. It's exciting because it enables us to provide better patient care and really see what's going on."

Prog1, Area VP: "We need to develop a relationship with our members and take away fear; this isn't about surveillance."

At the end of our meeting with the DNS at the second progressive home, we asked if she knew of a staff member who might be willing to show us around. She was wrapping up with some final comments about her managerial style and added that she would be willing to give us the tour herself: 
Prog2, DNS: "I'm the nurse for the staff but I have to get into everything. I need to take care of them, let them know they're important. Everyone's time is just as important as mine. We have no layers of staff here."

Similar to the first progressive home we visited, management at this home was interested in using the increased access to information as an opportunity to learn and improve overall efficiency. Again, the administrator in this case acknowledged the importance of shop-floor leadership:

Prog2, Administrator: "There's understanding, not close punitive monitoring. I am not a police officer. Not my role. You have to know what's happening on the floor before you hang your hat on what's happening with the computer." The DNS expressed a similar sentiment in terms of the need for a physical presence on the floor, regardless of technological advances. The purpose was not to use monitoring as a disciplinary tactic but as an opportunity to learn as an organization, with the aim of improving efficiency:

Prog2, DNS: "I'll know everything! To be forewarned is to be forearmed. I can start looking at solutions earlier and be more proactive. Most of the time it's not the person, it's the lack of support."

At the third progressive home we visited, we found a similar pattern of cooperative employment and labor relations, with the purpose of using the technology to stay ahead of the times and improve overall efficiency. Like the other progressive homes, the manager at this home also saw it as an opportunity to learn, especially the immediate and increased access to information.

Prog3, Administrator: "We're not out to get them but we're out to see that we have the best care. You may have a floor with, say, fifty residents but you didn't realize over the last couple years as your admissions came in, most of your residents on that floor are all a two-person assist. So each time that person 
has to get up, they need the Hoya lift and you're taking all of that staff and then they can't get their job done. So you're kind of setting them up for failure but that nurse may be afraid to come to her supervisor or the DNS to discuss it. [With] something like this, we'll have accurate information and more staff; certain floors may need it."

Prog3, Asst Administrator: "If you see (something) happening, now you know, go look for the reason. Maybe we need another nurse there. Or maybe we need to switch the nurses. Maybe we weren't capturing all of the needs and it's getting so busy that you need to put on more staff."

The general pattern was that progressive homes tended to view monitoring through a learning lens to check their own systems and improve efficiency, rather than as a disciplinary tool to identify and punish wrong-doers.

Proposition 2a: In progressive homes, little attention is paid to divides among and within classes of labor and management. Styles of discipline encourage those with supervisory roles to identify problem areas and improve learning among employees. Decision-making is collaborative, lending itself to an atmosphere of skill development and opportunity.

\section{Participatory Homes}

Shortly after we walked into the first participatory home, we were introduced to the administrator, a well-dressed and professional looking man who greeted us with enthusiasm. We were brought to a smaller conference room where the administrator sat and talked with us. What began as informal chatting turned into a lengthy interview about the nursing home and his managerial style. From our conversation, we sensed that organizational hierarchies existed only to the extent that roles could be defined by professional affiliation: DNS, RNs, CNAs, etc. In practice, however, these roles were not rigidly delineated. 
Part1, Administrator: "It used to be 'us vs. them' about 5-7 years ago but it's different now."

Instead of top-down or even collaborative decision-making between labor and management, employees were largely involved in these workplace processes.

Designating go-to leaders on each of the floors became a more effective way to reach employees, gain trust, and ultimately achieve great productivity. When we spoke with the DNS at this home, she described how her managerial style had changed over the years to accommodate this high performance type work system. She had recognized over time that this reaped greater organizational benefits than an authoritarian type system where management and staff were constantly at odds. She also noted that the administrator had experienced a similar transformation and that the home overall was now more geared towards empowering employees.

Part1, DNS: "I went to another place where the technology was in place, then came back and felt like I was in the dark ages. I can reassure them that, if I can do it, they can do it. It will give more of a self-appreciation, confidence, and more time to chat."

We got a similar feel at the second participatory home we visited, where management also emphasized empowerment, learning and skill development. When my colleague asked the director to tell us a bit about the home, he responded proudly:

Part2, Director: "We try to inspire people and do things differently. We don't want to go backwards with technology. We've been using touch screen, care chip technology, CNA resident assessment. We presented it at a tradeshow but people were afraid because it would show 'dirty underwear' - if a nurse missed something, they'd know. Well guys, that's the point. Now the health department has changed. They realize the importance." 
In each type of home, administration revealed another layer of managerial style through various statements made in response to questions about using the technology as a surveillance tool. In the participatory homes, to the extent that the technology would monitor behavior, it was viewed as an opportunity to learn how to improve what they were doing, both on an individual and organizational level.

Part1, DNS: "Expectation is positive rather than punitive. We can use it as an audit tool but it needs to be more of a teaching tool. The way it was years ago, it would be punitive, but we have open management here."

Part2, Director: "First feeling from the aides was, 'oh they're going to be watching us,' but I think the union has helped to neutralize that. It depends on how you present it to the staff. It needs to be presented as a tool for them and less paperwork."

Part3, Asst Administrator: "We'll look at our system first and see if the employee(s) need additional training. It is surveillance but...it won't be used in that way. It won't be punitive."

While each type of home had the overall goal of improving productivity and resident care, the medium through which participatory homes aimed to achieve this was by empowering their employees through learning and skill development.

Part1, Administrator: "Education from this will be phenomenal. It will make people better at doing their jobs."

Part2, Director: "It will enhance the camaraderie, the teamwork. In designing a care plan, they can do it at their own convenience."

Part3, Asst Administrator: "It will be easier to find trouble spots and patterns. This makes you look at your system. "

As mentioned earlier, employees in participatory homes were more involved in the decision-making and every-day work routines on the floor. Management found 
that this served as a more effective means of reaching employees, gaining trust and achieving greater productivity.

Part 2, RN: "I hope that we're not concentrating on checking (working on computer and not taking care of patients). Because we have a lot of psych patients and when they don't get their meds we're in trouble!"

Proposition 3a: In participatory homes, organizational hierarchy is viewed as a positive, where the involvement of different classes of labor and management is encouraged. The style of discipline is to use the identification of problem areas as a measure for organizational self-check. Decision-making is done primarily by the employees from the ground up, and the atmosphere is one of opportunity for both individual skill development and the improvement of organizational systems.

\section{2) Staffing}

\section{Authoritarian Homes}

Pay was lower at the first authoritarian home we visited than it was in any other home in the area. It was surprising, then, that turnover wasn't more of an issue that people stayed on despite poor working conditions, low pay and close surveillance. Interestingly, when we spoke to some of the employees about labor relations in the nursing home, most seemed content, if not accustomed to, this style of management. Most of the employees we spoke to had been there for twenty, twenty-five, or thirty years. When we inquired about this, we discovered that some had simply grown into their routines and that others in fact appreciated the paternalistic managerial style; having more ownership in the decision-making process might increase the risk of being held accountable for something. A few just needed to make enough to put their kids through college and didn't want their job security to be threatened, however meager it may have been. Some just enjoyed their work and, in a sense, tuned out 
whatever else was going on in order to get the job done and maintain some kind of livelihood for themselves and with the residents. The barriers between groups and within subgroups seemed fairly clear, yet the home continued to compete.

When we asked the administrator at the second home about her thoughts on how the technology might lead to layoffs, she replied:

Auth2, Administrator: "I could see a reduction in staff but not in medical records (that's not union). There have been a lot of cuts lately but not in direct care."

Proposition 1b: In authoritarian homes, recruitment and retention is moderately difficult and teamwork is low, creating a poor staffing situation in which employees are overburdened and have low morale.

\section{Progressive Homes}

Front-line employees at the authoritarian homes had a variety of complaints about relationships between subgroups of staff, but not many talked about their staffing situations specifically. In a way, they seemed content with the way things were, or perhaps unaware of their ability to effect change in the home. In the progressive homes, however, staff at all levels tended to contribute to the staffing debate. To varying degrees, each home had staffing issues, sometimes with retention but more often with recruitment. Some spoke about the ways in which they felt the technology might improve the staffing situation, while others reflected on the declining state of the field and the inherent difficulty this presented for recruiting.

Prog3, Administrator: "We've got EMRs, we are more focused on patient care, spending that kind of money and we're into technology so chances are we have better care than our neighbors." 
Prog3, Asst Administrator: "We're not waiting until 2014 when everybody has to; we're ahead of the game. I think we can use it to advertise that we are a modern facility."

During this interview, we learned that there had been high turnover in this position and that the current administrator had been at this home for only two years. When we inquired further, he said the turnover generally had to do with opportunities for moving up, which were positive experiences all around, and that his transition had been a good one. In an interview later on with the assistant DNS, this topic of high managerial turnover came up again, and she appeared to share a similar sentiment in terms of it having been a smooth transition:

Prog3, Asst DNS: "They (management) just tend to go along with the flow, just to keep it going in the same direction."

Staffing on a non-managerial level, however, was a more difficult situation. Some commented on the nature of the field while others referred specifically to their own frustrations in trying to recruit and retain staff members.

Prog1, DNS: "Some folks are intimidated by technology and might run away, and that's okay. Recruitment is easier than retention because of the limited number of nurses in market. But retention is decent already; if people leave it's for relocation purposes."

Prog2, DNS: “The job is not attractive. There's a lack of respect, there are low allocations, and yet people want more these days (entitlements and wish lists). People are sicker, but living longer, and they have greater needs. It's a female dominated profession, people aren't going in to it anymore, and quality people have low commitment. Staffing is a major issue. It's worse than in the past and it gets worse every year. Can't seem to get past that. I go to bed and have nightmares about it! 
Prog2, LPN: "People come for orientation and then don't come back because the workload is too heavy. For the past 3 months, I've been working 16 hours per day because of the staffing shortage. That is dangerous for both the residents and for my license. My work is demanding."

Prog3, CNA2: "I think that we don't have enough people to take care of the residents properly. I think it's just too many people. I have twelve residents to look after. We have fifty-eight people on our floor and we have five CNAs." When we inquired as to whether or not having EMRs would improve recruitment and retention, staff at all levels agreed that it would. Even though some were concerned with the technicalities of learning the system, many employees looked forward to the technology as a way of ultimately lightening their load, and administrators looked forward to it as an opportunity to improve retention.

Prog2, LPN: "Maybe it will allow administration to look clearly and see that more staff is needed. The technology would attract me as a new employee." Prog2, DNS: "Having the new technology might provide an added attraction, it will be more classy, there will be less paperwork, younger generation more attune to the technology. Technology is transferable. You take this knowledge with you. Behooves all of us to take it. Increases marketability. You are more expensive today than you were yesterday."

Prog3, Asst Administrator: “[Staffing] is an issue. It's very difficult to keep good staff. It's very difficult to encourage staff to come in to the building on the nursing end whereas EMRs just may do it because everyone wants to be a part of the future. We have a lot of longevity in this facility. The older staff members that are here, some are here for as much as 30 years. The newer...they come and they go. So this could help to hold on to them because they're busy learning this and it's a whole different world." 
While the staff were eager for the time-savings and subsequent reduction in stress that the technology would provide, they didn't seem to be phased by the idea of the technology interfering with familiar constructs of good employment relations such as good communication, and job security.

Prog1, DNS: "Hopefully this will help to recruit higher end staff but I don't know. They may be technologically [savvy] but that doesn't allude to their character."

Prog2, charge nurse: "Technology will have no impact on how I communicate with the staff. Whatever they input, they still have to tell me."

Prog2, CNA: (in terms of how the technology will affect her job) "It's going to be the same thing. Work will be the same, just how you report it will change. We were told there wouldn't be layoffs."

Proposition 2b: In progressive homes, recruitment and retention is moderately difficult, but teamwork is good. Employees are still overburdened but have improved morale as a result of the help they receive from co-workers, alleviating some pressure and creating a moderate staffing situation overall.

\section{Participatory Homes}

Walking in to the first participatory home, it was clear that we were dealing with a different resident demographic, primarily as a function of the location and the income of the families placing their relatives in the home. The lobby was classy, airconditioned and fairly quiet. Employees walked by with smiles on their faces, not rushing to get somewhere, not too pre-occupied with their work to say hello to us when we walked in. When we walked in to the second participatory home, we were greeted by a quite jovial security staff group who seemed to be happy with their work and with each other. When the director came in, his charisma and amicability were 
evident; he seemed like a busy person who always had time to ask everyone how he or she was doing.

Staff at the participatory homes recognized a basic need for positive relationships with each other, regardless of whether or not there was technology in place, for the overall well-being of the working environment. Employees at participatory homes reiterated the importance of teamwork without hierarchical discrimination. This was in stark contrast to the first authoritarian home we visited where there were extremely low levels of accountability and resentment between employees with supervisory roles and those without.

Part2, DNS: "There are staffing shortages everywhere but we [look out for] one another. If a nurse [a CNA] doesn't come in, a manager [an RN] fills in. There's teamwork and support. They just jump in the slot."

Part2, CNA: "Some of the coworkers need to unite a little better. We've got psych and bipolar residents. We're all here for a job. When you come in with an attitude, you can't work."

Part3, LPN: “[The technology] won't change my relationships with the staff. It will just take time. But I'm very positive about it. I really want this and I think it's going to be good for us."

Part3, CNA/orderly (22 years): "This home is the best - the staff, the whole environment, once this new management came in. We'd have patients who would come in here and couldn't do anything and then [we'd see them] walk out of here. It's good because you see how this place helps people get back to living a normal life."

Part3, Administrator: "We want to make things easier for the staff. We would have done it without the grant. We were looking for it; then the grant came in handy." 
Again, staffing was an issue at each type of home but the difference in how labor and management approached this issue demonstrated levels of cooperative employment relations. On the floor level, employees in participatory homes recognized the need for teamwork in alleviating some of the pressure of the paperwork requirements. At a managerial level, administrators recognized that they too had to do their part in making the working environment more amenable to producing quality care, which meant looking after their employees. By introducing the technology as an educational opportunity to their staff, they sent the message that they cared not just about improving productivity but also about contributing to their employees' individual skill development.

Part3, Administrator: "Hopefully it will help the staff in taking time with their functions, not rushing. It will make the home more organized and it will focus the care. The staff won't be strapped down by the paper, and there should be fewer accidents without pressure of time."

Part1, Administrator: "We push patient care but this is really measured by tasks and productivity since we are so heavily regulated. You need to spend money to make money, so we're driving revenue as opposed to cutting expenses. We're not going to use the technology as a tool to decrease staff; they will be reassigned to patient-care roles. What they already do on paper, they can do differently (more efficiently) with the technology."

Proposition 3b: In participatory homes, recruitment and retention is moderately difficult, but teamwork is high. Although the workload is heavy, increased help from co-workers lends itself to improved morale and a better overall staffing situation. 


\section{3) Breakdowns in Communication}

\section{Authoritarian Homes}

At the first authoritarian home we visited, despite complaints about the workload being too heavy, staff did not offer to help each other. There was a lack of teamwork and cooperation because of the employees' fear of repercussions. If someone helped out and something went wrong, he or she would be to blame. This fear of discipline, perhaps deriving from an authoritative managerial style, led to a lack of accountability and breakdowns in communication that left staff at odds with each other.

Auth2, Physician: "I don't know if we'll ever get rid of the communication problem between staff, RNs and physicians, especially at a top level. It could limit physicians' ability to be outside the template. [It could take away from the] voice recognition [they currently enjoy]."

Later in our interview with this same physician, as we got further into our discussion about the anticipated benefits of implementing EMRs, he provided some insight into how he felt the new technology might improve communication in the home:

Auth2, Physician: "[With EMRs] we won't be running around. It's like a zoo in there! We can see it in black and white. Penmanship [will also improve]. Medication can be properly [prescribed], etc. It will speed things up, [and information] won't get lost in system. In terms of quality of care, it will help a lot. It will hopefully change overall communication."

In addition to feedback we received from employees during our interviews about some of the hostility that existed between subgroups as a result of these breakdowns in communication, we got a sense of how this affected their working environment during a rather chaotic meeting between management and the 
representative for the technology vendor. While management in this home was clearly excited about the benefits that would come with the new technology, the communication needed to get everyone on board was lacking. As the physician there had pointed out, it was "like a zoo in there", and we caught a glimpse of this in what was supposed to be a simple meeting between the DNS, physician, and technology representative. We didn't interview the representative; we just sat in on their fairly disorganized meeting. She was forty minutes late, apparently caught in traffic, but the message hadn't been relayed to the administrator. She couldn't follow through with her presentation because it required a wireless connection and there wasn't one at the home. The meeting was held in the DNS's small office, a radio was playing out in the lobby, and salsa music was playing in the recreation room on the other side of the wall. Multiple conversations were going on at once and the representative didn't seem able to answer the questions that the physician and DNS were asking her. She was curious about our presence but we reassured her we were just there for informative purposes and to learn a little more about the process. Somewhat suspiciously, perhaps based on the flow and overall atmosphere of the meeting, she took our names and contact info afterwards. Despite the chaos we were witnessing, the administrator reflected positively on the state of employment relations in the home.

Auth2, Administrator: "[We have] very excellent staff, they're willing to learn, and are open to ideas. I have an open door policy, and people come in and tell me their problems. Of course everyone has a few bad apples. People are happy here. We have low turnover, and longevity. It's a nice staff." It was interesting to hear her speak this way about her staff, in contrast to the impression we got when we first arrived at the nursing home. When we walked into the lobby, the receptionist didn't phone or go speak to the administrator to let her know we had arrived. She just spoke louder to a room across the hall, where the 
administrator seemed entirely unenthused (perhaps even put off) by this announcement. The administrator was shuffling around, tending to some business, rearranging papers and boxes, and moving slowly. When we finally began our conversation with her regarding her opinion of the new technology, she responded somewhat pessimistically:

Auth2, Administrator: "I think there will be pounds of errors made in the beginning. I'm worried about technical errors and staff making mistakes. I worry about everything, that's why my boss loves me."

This is said right after she receives a phone call from someone looking for assistance, redirects them and hangs up, sighs, and rolls her eyes. She continues:

Auth2, Administrator: "I have my reservations - there are pros and cons. [The technology] won't help medication errors at all. [You can] scan it, but you could scan the wrong medication. I'm not sure that it will improve that much. [Where it may help is in being able to spend] more time with the residents turning, and eating. I want nurses to be more gentle. It will probably save time for them to do more of their job, not more jobs. That's all I know, the rest who knows about."

When we followed up with the DNS about the administrator's belief that EMRs would not alleviate medical errors, she concurred:

Auth2, DNS: "I'm hoping [that there will be] more time with the residents, that errors will decrease, and pharmacy communication [will improve]. But I don't think it will help with the problem of potential errors."

She then gave the example of two medications accidentally going to the same person because two reports were stapled to each other, emphasizing that the same thing could happen with EMRs. 
Proposition 1c: In authoritarian homes, the flow of information is low, as are levels of trust. This leads to frequent breakdowns in communication and creates an atmosphere of fear and hostility.

\section{Progressive Homes}

In contrast with the surrounding area and neighborhood, the feel of the second progressive home we visited was surprisingly modern and well-maintained. It was like walking into the lobby of a nice hotel, and we were welcomed instantly into what appeared to be an open and warm environment. We were greeted by the people at the front desk and offered a seat in the waiting area. Shortly after we arrived, the administrator joined us in the lobby and introduced herself. She was a professional and cheery looking woman who welcomed us into her office. She highlighted the importance of communication and teamwork as keynotes of positive employment relations, as did several other administrators and front-line employees in the progressive homes. The assistant administrator in the third progressive home proudly stated:

Prog3, Asst Administrator: "What sets us apart is the team. Everybody is involved. The office staff are family members. You don't always find that. You usually find closed doors in offices. You find quarters with blinders, [where the staff] doesn't see the residents as they clean. It doesn't happen in this facility. It starts from an administration that cares. And everybody in this facility cares."

Prog3, CNA1: "On the floor that I work, the fourth floor, the communication is excellent. We ask one another questions and we listen to everybody's ideas. You cannot work with a person and not have any communication. It is [unique]. It's a family. What I like about management...they relate to us. They talk." 
Prog3, DNS: "We (the workers) are okay, we're good. We work as a family."

Prog1, Contract Administrator: "Everyone gets along. They're outspoken and there's good communication; management hears about it. There's a go-to person on each floor."

Not only was communication recognized as an essential feature of a cooperative working environment, it appeared to be the nucleus of problem-solving techniques in these homes. At the third progressive homes we visited, we saw this at all levels of the organizational hierarchy:

Prog3, Administrator: "When I make rounds, they'll stop me on the unit and ask if [they can speak to me]. I talk to them and see what their concern is. On certain [occasions], they'll be wrong and I'll say, listen, let's work something out that makes sense for everybody. But really, it's not often [that there's a problem]."

Prog3, Asst Administrator: "You know, if they have a problem, they're going to get it addressed. We address all problems. They don't feel the need to go to the next level because we're fair."

Prog3, DNS: "We help each other. I go to the floor every day in the morning, so they (the workers) ask me even though I don't make rounds, and they ask me right then and there whatever problem they have."

Prog3, CNA1: “The administrator, no problem, his door is always open, you can come down here and ask him something. If I have a problem with equipment or something, we go through the department head. If they don't answer it, we go to the administrator. You know, we're like 'we need a microwave' and the next hour the microwave was in. We're lucky to have a good relationship with the administrator because a lot of facilities, they don't get along." 
Communication also played a key role insofar as administration needed to ensure that everyone was receptive to the new technology and on board each step of the way:

Prog2, Administrator: "We need to embrace change. It's never easy, but we've tried over the years to change. Sometimes it's traumatic. This is the biggest change, unlike programmatic changes. This is a major challenge but, based on our history, we should be fine. A lot of main players came together. We're progressive. I don't have to pull the whole way. Physicians are also very much on board; most of them are used to computers. This will be more efficient in terms of time and resources. If the staff can get done faster, more hands on care."

When we spoke with the DNS at this home, she seemed very accommodating, pleasant, helpful and respected, both in her responses and in her composure.

Prog2, DNS: "I'm open to the new technology, receptive, no expectations. We have five physicians and whatever I tell them to do they do it!" (she says with a smile on her face). "We're a good team, and we work together. Stable [longterm] leadership can be a negative but it's a positive here. We always try to stay with the times, to be current and marketable. We go to every seminar, we network, [and we're part of the] administrator's society/coalition. I meet with every resident to determine if we can meet their needs. I know the residents." It was interesting to hear the examples she gave of what she knew about the residents (e.g., . whose son ran away, whose daughter was in jail, who was pregnant), which was perhaps a reflection of the demographics of that neighborhood.

When we asked the front-line staff how the union interacted and addressed issues with both them and management, we found that their responses revolved around consistent trends of ongoing communication and treating each other like family. 
Prog3, CNA1: "You can't make something work without communication. [Our relationship with the union is] great. This is my policy: you must get along with the people in house because you never know when you're going to need them to fall back on. You gotta have a good relationship and I can honestly say that we have a good relationship with management. Our DNS is the best."

Proposition 2c: In progressive homes, the flow of information is moderate, as are levels of trust. Breakdowns in communication occur but the outlook is positive, using these mistakes as an opportunity for training and improvement.

\section{Participatory Homes}

In the second participatory home we visited, the director introduced us to a young woman who assisted him with administrative logistics and events. On this day, she was in charge of showing us around the home. He told us that he hired her from Israel and that his decision was based on the fact that she had been an apple picker and had served in the Israeli army. The young woman had been working at the home for only two years, but demonstrated confidence and a personal connection with each staff member and resident. Even as an administrative assistant, her amicability and involvement on the floor level was a powerful illustration of an ongoing organizational mandate to promote communication and positive relationships throughout the home.

In addition to encouragement from the top level, we found that employees were encouraged to find ways to motivate each other. There was evidence of "high performance" employment relations in what several employees had to say about the nature of their relationships both among and within management and front-line staff. Themes that were commonly discussed had to do with employee involvement and teamwork. 
Part1, DNS: "We use employees' leverage to get others to perform, not my own."

The above DNS referred to an employee recognition program that they had in place. A CNA at the second home supported a similar cause by stressing the importance of working together.

Part2, CNA: "We've got 40 females [on staff]. We need to be able to go up and down on attitudes. There is no technology for that! [Administration has] a very good rapport with everyone. They listen if you have a problem."

She seemed more willing and available to meet with us than some of the others. When we had tried to meet with other employees on the floor, most had only four or five minutes to speak with us, hurriedly tending to their tasks. Even from those brief conversations, however, we were able to gather a few comments that reflected the overall outlook on the importance of communication in all aspects of the home, from methods for resolving problems to making sure everyone understands how organizational change affects their rights and benefits.

Part1, Administrator: "We didn't really have an active labor-management committee before this but there has always been an open door policy."

Part1, CNA (in charge of recreation): "The member isn't always right. Incorporating [the technology] in to a new contract, some are concerned about maintaining benefits. We need to get the facts straight though, so as not to spread rumors."

Part2, Director: "There are a lot of meds here, so the interface with the pharmacy and doctor will help. The pharmacy will keep the doctor current." Part2, DNS: "Time is productivity. [If this allows us to save time], we will be able to produce more. [That is to say, we will have] better productivity and 
care giving. We will have better service, fewer errors, better communication with the various disciplines, and better quality of care."

Shortly after we began our interview with the administrator at the third participatory home, we were joined by the assistant administrator. Her dominating personality came through even in her positive statements about how the employees felt about the new technology.

Part3, Asst Administrator: "Employees are excited; but they're being shielded from the trauma behind this."

This was interesting given that we expected that participatory homes would be less paternalistic in how they disseminate information to their staff. In this case, the assistant administrator clearly had good intentions about the implementation of the new technology, but was going about it with a more authoritarian undertone than might have been expected. This is just one illustration of how a home can have an open door policy but not necessarily allow a high flow of information. For whatever reason, the assistant administrator at this home felt it would be most beneficial to inform the employees only so far as that information would be helpful to them and the organization. She allowed the staff to be involved but chose not to suggest anything that might intimidate them or make them nervous about the process of implementing EMRs - a strategic choice to facilitate the smoothest transition possible.

Proposition 3c: In participatory homes, the flow of information is high, as are levels of trust. Communication is a key feature of both workplace relationships and problem-solving systems, creating an opportunity to improve as an organization overall. 


\section{4) Attitudes Toward Temporary and Older Employees}

\section{Authoritarian Homes}

In terms of conflict, another common theme emerging in authoritarian homes had to do with the divide between younger and older staff. The following statements are a reflection of these biases:

Auth2, Administrator: "Oldies don't like the newies because they want to do it their way."

Auth2, LPN/charge nurse: "We have a younger crowd. They don't like rules and regulations, so they bounce (go away). The younger age group work from 7 am to $3 \mathrm{pm}$. The second group (which works from $3 \mathrm{pm}$ to $11 \mathrm{pm}$ ) is more nervous than the first group. They feel like it's too late to learn."

Curiously, our meeting with the CNA from the labor-management committee was set up in the office directly adjacent to the DNS's office, with the door propped open. She seemed mildly hesitant but, when asked how she felt about the new technology, she responded:

Auth2, CNA from LMC: "It's about time the nursing home does something. It's a good thing, to upgrade. Sixty percent of the staff is enthusiastic; the others are not as excited (older heads). Older heads don't like it, to adjust from paper. They feel like they won't grasp it."

When the same CNA was asked how she felt about being monitored, she replied:

Auth2, CNA from LMC: "It's okay if you're accustomed to doing the right thing. But the older ones don't like monitoring. They're worried because you can't leave a space and then go back the next day to fill it in or to make a note; it needs to be done right away [and that isn't necessarily happening with the paper method]." 
Similarly, when we asked an LPN what she thought the nursing home would look like when we came back in a year, she was optimistic:

Auth2, LPN/charge nurse: "A year from now, everybody will be more comfortable, and might even be asking if technology can be doing more. [There will be improved] resident care, more hands due to less paperwork; and better care than they're able to give now (one on one)."

There was also an issue about perception of temporary employees, from the viewpoint of both management and front-line staff. Nurses were concerned with the high turnover of staff from agencies that supplied temporary employees. Someone would come in one day and the nurses would be in charge of training him or her, only to have that person return intermittently, if at all. To the nurses, this produced poorly informed employees on the shop floor and was a waste of the limited time they had to take care of their own routine tasks. Not only did this include providing care to the residents but, as we've mentioned, staying late to complete overwhelming amounts of paperwork. Management tended to share this perspective yet also recognized the importance of being able to have the extra help if necessary. The DNS at the second authoritarian home offered some insight in to the home's attitude towards temporary employees.

Auth2, DNS: "We don't take temp CNAs from outside because they don't know what's happening. Sometimes I will take one temp (LPN) and she's mine. I know how to keep her mouth shut so it's okay."

Proposition 1d: In authoritarian homes, the attitude towards older and temporary employees is negative, creating an atmosphere of hostility, frustration and fear. 


\section{Progressive Homes}

There was some hesitancy about the new technology among the older and computer illiterate population in progressive homes, which was similar to the authoritarian homes in some ways but different in other ways. We heard the DNS in one authoritarian home speak firmly about disciplining those who were not doing their jobs properly, stating:

Auth1, DNS: "I may give them an in-service, then a warning. If they don't like that, they can find a job somewhere else."

While progressive homes were also aware that the new technology would capture all that was happening, they had more of an appreciation for the learning curve that existed between young and old employees, as well as those who were computer literate and those who were not. Rather than focus on punitive measures in resolving these conflicts, they placed a heavy emphasis on education, allowing each individual as much training as they needed in order to feel comfortable.

Prog1, Contract Administrator: "There's an 'old heads crowd' here but we mostly have a younger base. Expansion has been at a steady pace."

Prog2, Administrator: "Overall there has been a lot of enthusiasm, more so among younger population. It has taken longer than we thought for the older crowd to get comfortable with the technology. We had to extend training."

Prog1, DNS: "There has been some anxiety among staff but our leadership is all excited about it, and folks are ready."

Prog3, Asst Administrator: "You know, there are a lot of older people here, so they're a little leery of what's going to go on it and who's going to see it. So we'll need to calm the fears but, for the most part, they're just excited to get their hands on it and how much time it's going to free up for the nurses to do hands on care versus paperwork." 
Prog2, DNS: "A lot of people are not computer literate and this program is complex."

Although the issue with older employees was present in both authoritarian and progressive homes, how management chose to approach the issue differed. In the progressive homes, rather than express concerns or frustration with the older population, administrators reinforced the need for training and continual support. Teamwork and keeping everyone on board was emphasized as a necessity. In one way or another, both labor and management at each of the progressive homes referred to their staff as being a team and a family.

Prog1, Administrator: "Leadership has to stay connected, give guidance and feedback. We want to stay true to the original intention of the software. We need someone to keep reinforcing what we need to do, otherwise [all we have is] a jumbled electronic version of a chart. We'll get over the initial hurdles but we need to stay committed to it. You get out what you put in. We're realistic about bumps in the road."

Aside from the issues with older employees, there was also a concern about younger employees from those who had been in the field for a long time. While the younger crowd may have been less hesitant about learning to use EMRs, there is a crucial hands-on piece to resident care that no amount of technology can replace. We heard one CNA reflect on this experience:

Prog3, CNA2: "My years of experience make it able for me to do what I need to do. But a young person coming in, I see them struggling because they don't have enough time to do what they need to do and get out of here by three o'clock. They're lagging behind, this is not complete, or that wasn't done."

In contrast to the authoritarian homes, staff and administration in the progressive homes viewed temporary workers as an important asset to their homes. 
There were only a small handful of exceptions, primarily in reference to the amount of work that an agency employee could accomplish in the same amount of time as a fulltime employee. In progressive homes, employees from an agency were regarded and treated with the same respect as full-time employees, again reflecting the 'family' mentality of staff across the board:

Prog3, Asst DNS: "We don't have a lot [of temp staff] that just come in and leave. They like being here. We don't have a fast turnover. Usually they stay. The staff here, they really stay."

Prog3, CNA1: "Agency employees, you got to treat them with all the dignity and respect because to make it work everybody has to have some type of communication."

Prog2, LPN: "Even if I only worked one shift, someone from the agency will come in and only get half of the work done, so then I still have to catch up."

Proposition 2d: In progressive homes, the attitude towards older and temporary employees is moderate, or mixed. While these employees may be hesitant about change, management's goal is to educate, train, and involve them in the process.

\section{Participatory Homes}

Each home alluded to hesitation among the older employee population, based on feedback about how well the older employees believed they would adapt to the new technology, how quickly they would learn to use it, and whether or not they would have difficulty due to issues with sight and dexterity. The participatory homes were no exception but had a different outlook on how to address this issue.

Part3, LPN: "[The technology is] bringing chaos into the home. There are mixed reviews [from staff about it]. Need to take a lot of things in to account. I have concerns about how licenses are going to be affected. [Right now] 
everything can be charted, and can be looked back to. There's a lot of hesitation among the older folks with the technology. [For example, during the training] someone couldn't see the computer."

Part2, DNS: "If somebody isn't good at it, we must teach them. Might be like the tortoise who comes out ahead of the hare. We're a chain. If you break one link, we'll all fall."

Part1, RN: "The administrator is fair and the director is very good. I'm here 'til I die. I'm too old to move around."

As mentioned earlier, a recurring theme throughout each type of home was a concern with whether or not to involve agency employees in learning the new technology and, if so, how they would be able to adapt. The participatory homes also shared this concern, despite their stronger emphasis on learning, skill development, and empowerment.

Part1, union rep and former CNA: "Topics [in our labor-management meetings] include mainly the anticipation of the technology. There is some apprehension, which might change only after implementation. People are interested but concerned they won't understand it or might get in trouble, but they do want to go forward with it."

Part2, LPN: "Most residents are on a lot of meds, like ten to fifteen each. It will take a longer time with this system, more than the two hour window. We have a lot of agency people. There'll probably be a lot of confusion to begin with. Normally we'd be able to give meds as soon as possible and then go fill out the forms. Now we have to do it all at the same time."

Part2, DNS: "Technology always improves. How adaptable are we to the technology is the question. We need to show that technology will not be lost, and that you can take it with you anywhere you go. We do this in a few ways: 
imparting [information] and, for those who are scared, teaching them, being patient, and providing tutors (peer mentors). Without the grant, we would still be moving forward. We need to have some type of motivation, something to tell you you're not dead, you're still alive. This is what you must preach to the other people. You can't have a negative attitude or you won't get anywhere. I never really think negatives. Like if my car gets a flat, I think it happens for a reason because I may be avoiding an accident ahead. I may not be here in a year but it's just perseverance."

Proposition 3d: In participatory homes, the attitude towards older and temporary employees is positive. These workers are regarded with the same respect and dignity as full-time employees, creating a positive workplace atmosphere.

\section{Summary}

As illustrated in Table 2, I broke down the four workplace issues addressed in this chapter into two additional subsets, deriving from the intensity and frequency with which interview respondents spoke about these issues. Table 2 summarizes the observations from this chapter which suggest that different approaches to dealing with workplace issues play a significant role in creating, and re-creating, organizational climate. 
Table 3 Approaches to workplace issues in different types of homes

\begin{tabular}{|c|c|c|c|c|}
\hline \multicolumn{2}{|c|}{ Workplace Issues } & Authoritarian & Progressive & Participatory \\
\hline \multirow{2}{*}{$\begin{array}{c}\text { Organizational } \\
\text { Hierarchies }\end{array}$} & $\begin{array}{c}\text { Discipline } \\
\text { Style }\end{array}$ & Punitive & Learning & $\begin{array}{c}\text { Organizational } \\
\text { Self Check }\end{array}$ \\
\cline { 2 - 5 } & $\begin{array}{c}\text { Makision } \\
\text { Staffing }\end{array}$ & Top-Down & Collaborative & $\begin{array}{c}\text { Primarily } \\
\text { Employees }\end{array}$ \\
\cline { 2 - 5 } & $\begin{array}{c}\text { Recruitment } \\
\text { \& Retention }\end{array}$ & $\begin{array}{c}\text { Moderately } \\
\text { difficult }\end{array}$ & $\begin{array}{c}\text { Moderately } \\
\text { difficult }\end{array}$ & $\begin{array}{c}\text { Moderately } \\
\text { difficult }\end{array}$ \\
\hline \multirow{2}{*}{$\begin{array}{c}\text { Communication } \\
\text { Information }\end{array}$} & Plow & Poor & Good & Very Good \\
\cline { 2 - 5 } & Trust & Low & Moderate & High \\
\hline $\begin{array}{c}\text { Attitude } \\
\text { Towards Temp } \\
\text { and Older } \\
\text { Employees }\end{array}$ & $\begin{array}{c}\text { Older } \\
\text { Employees }\end{array}$ & Negative & Neutral & Positive \\
\cline { 2 - 5 } & & Negative & Neutral & Positive \\
\hline
\end{tabular}

In authoritarian homes, we saw that punitive styles of discipline lead to fear and hostility, and top-down decision-making left employees feeling uninformed and mistrusting. Recruitment and retention was moderate but teamwork was low, creating a poor staffing situation in which employees were overburdened and had low morale. The flow of information was low, as were levels of trust. This lead to frequent breakdowns in communication and created an atmosphere of fear and hostility. The attitude towards older and temporary employees was low, further adding to the atmosphere of hostility, frustration and fear.

In progressive homes, styles of discipline encouraged those with supervisory roles to identify problem areas and improve learning among employees. Decisionmaking was collaborative, lending itself to an atmosphere of skill development and opportunity. Recruitment and retention was moderate, but teamwork was as well so 
that employees didn't feel as overwhelmed. They were still overburdened but had improved morale as a result of the help they received from co-workers, alleviating some of the pressure and creating a moderate staffing situation overall. The flow of information was moderate, as were levels of trust. Breakdowns in communication occurred, but the outlook was positive, using these mistakes as an opportunity for training and improvement. The attitude towards older and temporary employees was moderate, or mixed. While these employees were slightly hesitant, management's goal was to educate, train, and involve them in the process.

In participatory homes, the style of discipline was to use the identification of problem areas as a measure for organizational self-check. Decision-making was done primarily by the employees from the ground up, and the atmosphere was one of opportunity for both individual skill development and the improvement of organizational systems. Recruitment and retention was also moderate in participatory homes but teamwork was high. While the workload was heavy, increased help from co-workers lent itself to improved morale and a better overall staffing situation. The flow of information was high, as were levels of trust. Communication was a key feature of both workplace relationships and problem-solving systems, creating an opportunity to improve as an organizational overall. The attitude towards older and temporary employees was high. These workers were regarded with the same respect and dignity as full-time employees, creating a positive workplace atmosphere.

In the following chapter, this relationship is developed further with a discussion about the role that perspective on conflict plays in shaping organizational climate. Specifically, I will illustrate how different perspectives on conflict are reflected in approaches to workplace issues, and will discuss the implications of this for the different types of homes. 


\section{CHAPTER 5: Discussion}

As mentioned in Chapter 2 of this thesis, research has shown that conflict can be viewed from a variety of perspectives, demonstrated especially in the work of theorists from the early $20^{\text {th }}$ century. Fayol (1916/1949) and Weber (1929/1947) argued that conflict is detrimental and should be eliminated. Follett (1926/1949) and Whyte (1967), on the other hand, asserted that conflict is inevitable and must be used for problem-solving and efficiency. A more functionalist perspective, offered by scholars such as Kerr (1964) and Miles (1980), views conflict in terms of how it inspires feedback, growth, and innovation. In this thesis, I have proposed that these different perspectives on conflict lead managers to address workplace issues in different ways, which plays a significant role in shaping organizational climate. Table 3 illustrates how these different perspectives apply to the workplace issues examined in this thesis, both in terms of the management style that stems from this, and the organizational climate that is generated as a result.

Table 3 Perspective on conflict reflected in management style and climate

\begin{tabular}{|c|c|c|c|}
\hline $\begin{array}{l}\text { Workplace } \\
\text { Issues }\end{array}$ & $\begin{array}{c}\text { Perspective on } \\
\text { Conflict }\end{array}$ & Management Style & $\begin{array}{c}\text { Organizational } \\
\text { Climate }\end{array}$ \\
\hline $\begin{array}{c}\text { Organizational } \\
\text { Hierarchies, }\end{array}$ & $\begin{array}{c}\text { Negative: } \\
\text { Conflict is bad. } \\
\text { Eliminate it. }\end{array}$ & $\begin{array}{c}\text { Top-down } \\
\text { decision-making, } \\
\text { punitive } \\
\text { disciplinary style }\end{array}$ & $\begin{array}{c}\text { Fear, hostility, low } \\
\text { accountability, trust, } \\
\text { teamwork, } \\
\text { communication }\end{array}$ \\
\hline $\begin{array}{c}\text { Staffing, } \\
\text { Breakdowns in } \\
\text { Communication, }\end{array}$ & $\begin{array}{c}\text { Neutral: } \\
\text { Conflict is } \\
\text { inevitable. Try } \\
\text { to work with it. }\end{array}$ & $\begin{array}{c}\text { Collaborative, } \\
\text { mistakes viewed as } \\
\text { learning } \\
\text { opportunity }\end{array}$ & $\begin{array}{c}\text { Increased awareness, } \\
\text { opportunities, } \\
\text { moderate trust, } \\
\text { teamwork, } \\
\text { communication }\end{array}$ \\
\hline $\begin{array}{c}\text { Attitudes toward } \\
\text { temps and older } \\
\text { employees }\end{array}$ & $\begin{array}{l}\text { Positive: } \\
\text { Conflict is } \\
\text { good. Can be } \\
\text { used to improve } \\
\text { organization }\end{array}$ & $\begin{array}{l}\text { High employee } \\
\text { involvement, } \\
\text { mistakes used for } \\
\text { organizational self- } \\
\text { check }\end{array}$ & $\begin{array}{l}\text { Empowerment, well- } \\
\text { informed, high trust, } \\
\text { teamwork, } \\
\text { communication }\end{array}$ \\
\hline
\end{tabular}




\section{Organizational Hierarchies}

Within nursing homes, there are several classes of employees, both union and non-union: administrator. Some of the nursing homes we visited used organizational hierarchies to exploit other classes of workers, sticking only to what they needed to do and pointing the finger when things didn't get done. Others saw less clearly defined lines between classes of workers, stressing the importance of everybody pitching in to keep the place running well and the residents cared for properly.

If organizational hierarchies are viewed as consisting of a variety of roles that create an opportunity for efficiently fulfilling tasks and cooperating with each other, this workplace issue could potentially work to the advantage of both the organization and the individual. The improved efficiency of the organization would have a positive impact on performance and resident care. The individual would be less overburdened and more satisfied with his or her job. On the other hand, if the variety of roles in a hierarchy were to be viewed from the perspective of holding more or less power, the division of classes might foster hostility towards each other. Ultimately, this could have a negative effect on both the organization and the individual. Individuals dealing with a heavy workload and bitter relationships would be less satisfied with their jobs and complete fewer tasks than they could if there were more assistance. As such, organizational efficiency would decrease and negatively affect overall performance, which could have repercussions for resident care.

In addition to looking at how labor and management view the different roles in their organization, it is also important to look at how administrators make decisions and what their disciplinary styles are. Workplace culture, attitudes and behaviors are a major determinant of the success of any organizational change. One important feature of workplace culture is the motivation that administrators have in adopting major changes. For example, how administrators choose to use the increased access to 
information that comes with electronic medical records is reflective of their managerial style in general within the nursing home. Some administrators view the access to information as a learning opportunity for them to check their own systems of operation and provide any necessary additional training for their employees. Others have adopted a more punitive style in which they view the increased availability of information as an opportunity to weed out the bad apples. From an employee perspective, knowing that your every move is being watched can be stressful and in turn have an effect on morale, job performance, and relationships with supervisors. It is important to address the motives behind administrators' choices to adopt the new technology and what plan they have for the continued application and maintenance of their systems. Implementation without real motivation or ongoing support creates a situation where conflict can lead to a negative workplace climate.

\section{Staffing}

The staffing situation in the nursing home industry is already poor, with recruitment getting tougher given what some perceive to be the declining state of the field. In each home we visited, staffing was an issue to the extent there were too many residents per nurse which made people feel overburdened and overwhelmed. In some cases, nurses viewed this as a reason for doing only what was required of them, sometimes out of fear of being held accountable for something they might do wrong, and other times so as not to burn out. This often led to hostile relationships between employees, as few were willing to help each other. Additionally, while recruitment and retention was an issue in each of the homes, when we asked why people stayed, it seemed the most common reason among nurses in authoritarian homes was out of job necessity and the feeling that they had limited other options. In the progressive homes, some were satisfied with their jobs while some stayed because they were afraid of making changes. Also, the attitude among nurses in progressive homes was 
that everyone was there to make sure the residents received the proper care, whether that meant covering for another employee or doing a task that was someone else's responsibility. This appeared to have a domino effect, where one person's willingness motivated others to pitch in as well. Even though many were overburdened, morale was improved knowing that a group of people was there as a support system.

Likewise in the participatory homes, morale was high and people tended to stay because they were genuinely happy with their jobs, resulting from an emphasis on teamwork and making sure the staff felt appreciated.

\section{Breakdowns in Communication}

Breakdowns in communication can happen in any type of organization. In some homes, not knowing what was going on created a sense of confusion and hostility among employees who felt that decisions were only being made at the top. In other homes, this same situation was viewed as an opportunity to ask questions and become more involved. Where management chose to involve employees and open up the flow of information, there tended to be increased awareness, which facilitated a high level of trust in the home. The more informed, the more trusting the employees appeared to be and the smoother the operation of the facility.

Implementing major organizational change is a prime example of where good communication is necessary, especially where the implementation of technology is involved. As we've seen in other industries, the introduction of technology has a tendency to lead administrators toinstitute layoffs, in an effort to maximize efficiency. Throughout the course of our research, several people outside of the project have inquired as to the involvement of the union. It seems counterintuitive that a union would be supportive of a major technological advancement in an organization that thrives on interpersonal interaction, communication and hands-on care. 
An important finding was that most administrators recognized just how crucial it was to have the union on board so that their employees didn't perceive the change as something management was arbitrarily imposing on them, thus increasing trust and lowering resistance. They recognized that their staff might be nervous with the idea of a major organizational change and that trust would be better built if they knew the union was working closely with management. Having the union on board facilitated collaboration among the variety of groups in the nursing home, particularly in homes that were accustomed to having a good flow of information. In those that did not, it was not always clear to the employees what effect the new technology would have on their workload or their positions in the homes.

\section{Attitude Towards Temps and Older Employees}

With any organizational change, some employees are going to be more fearful or receptive than others. Issues of fear around change could lead to a decrease in employee morale, which may in turn have a negative effect on job performance. In the authoritarian homes, some employees expressed concern over the ability of the older employees to learn the new technology and adapt accordingly. They were worried about them making mistakes and, in a few cases, mentioned a concern that some might leave because they would be afraid of having to use something they wouldn't understand. They also voiced serious concern about the idea of temporary workers being trained on the new technology. The thought of someone coming in for a day and allocating time and resources to their training, only to have them leave and never come back, was discouraging to say the least.

In the progressive nursing homes we visited, most nurses felt that everyone should get trained on any new technology. They wanted everyone to be on board, and for the older employees and the temporary workers to know what was going on. It was important to them that all levels of nurses be part of the new advances. While 
there was some concern about how smoothly the transition would occur, there was more reaching out to subgroups of employees than there was in the authoritarian homes, creating better workplace relationships and an environment for improved productivity.

Similarly, employees at the participatory homes viewed temporary and older employees with all the dignity and respect of full-time or technologically savvy employees. They recognized the necessity of everyone's contribution to the home and were able to capitalize on this by allocating the appropriate time on training that each individual required in order to feel knowledgeable about the new technology and comfortable with it as well, whether that translated in to one week or four months.

\section{Implications for Different Types of Homes}

\section{Authoritarian Homes}

In authoritarian homes, conflict appeared to be viewed as a negative. The underlying assumptions being that conflict can damage relationships between labor and management or within subgroups of employees. It can create organizational hierarchies and hostility, lending itself to breakdowns in communication that disrupt the flow of important information, ultimately weakening organizational efficiency. Authoritarian homes used punitive disciplinary tactics and paternalistic styles of decision-making to run their homes. The staffing situation was poor in each type of home but there was very little teamwork in the authoritarian homes in order to ease the workload or improve the climate for recruitment and retention. Communication was low, as were levels of trust and attitudes towards temporary and older employees. Decisions were made in order to gain tighter control of the staff and, in particular with the implementation of EMRs, the goal was to heighten surveillance and discipline. 


\section{Progressive Homes}

Progressive homes seemed more neutral towards conflict, focusing on addressing conflict in a collaborative way, and viewed all experiences as a learning opportunity. They aimed to make things easier for their staff by involving them in the decision-making and creating an atmosphere where people believed they could lend a hand to one another without fear of repercussions. Communication was more horizontal than top-down and attitudes toward temporary and older employees were much less hostile than in the authoritarian homes. A monitoring theme again emerged but the increased access to information was considered a learning tool.

\section{Participatory Homes}

In participatory homes, conflict was viewed as a positive. Conflict can force employers to look at their own systems in order to see what they can do differently to make life easier and more functional for all parties involved. Management focused on working through problems and creating systems to prevent further conflict, always looking for better solutions and new innovative ways of doing things. Teamwork and empowerment were key features of the workplace, communication was high, and temporary and older employees were regarded as an essential part of the organization.

\section{Conclusion}

The guiding research question we examined was how organizations with the same types of workplace issues are able to experience vastly different organizational climates. This thesis supports previous research that has demonstrated a positive relationship between management style and organizational climate and, furthermore, adds to the literature by suggesting that managements' perspective on conflict plays a key role in shaping their managerial style. By looking at how different styles were reflected in approaches to a variety of workplace issues - including the way discipline 
problems are handled, how decisions are typically made, and the use of teamwork we were better equipped to articulate this link.

These observations illustrate that the existence of certain types of workplace issues alone does not necessitate negative consequences, unless they are viewed in a negative way. Administrators and organizational leaders have some influence in shaping workplace climate by changing their approach to dealing with workplace issues. This approach, or management style, is proposed in this thesis to be largely influenced by management's perspective on conflict. Where conflicts are viewed as opportunities for growth and improvement, the work environment will be more conducive to fostering a sense of empowerment and learning on both an individual and organizational level. This is the type of climate in which employees can thrive and, subsequently, in which organizations are better able to embrace organizational change. 


\section{APPENDIX A: \\ Nursing Home Field Research Protocol: Management Interviews}

\section{Motivation and incentives for participating in the project}

a) What was your central motivation for adopting the Medical Records Keeping technology?

b) Would you have participated in this project in the absence of the state subsidy?

c) How do Medicare and Medicaid reimbursement schemes factor into your decision to participate in the project?

d) Is recruitment and retention an issue for your nursing home? If so, is the introduction of the technology linked to either of these issues?

e) Are there other incentives driving your participation?

\section{Expectations from participating in the project and other associated outcomes}

a) What effects do you think this technology will have on your nursing home?

b) How do you think this technology will affect your residents - their overall condition and their care?

c) How do you think this technology will influence employees and their work?

d) Will the technology affect staffing levels in your nursing homes? If so, in what way?

e) Do you think the technology is going to influence job security?

f) How will you make use of the time saved on paperwork?

g) Will this technology give you a competitive advantage over the Nursing Home down the road which has not implemented electronic medical records? 


\section{Labor Relations}

a) How would you describe the nature of labor relations in your industry?

b) How would you describe the nature of labor relations at the nursing home level?

c) What are some of the key issues that you and the union engage over?

d) What are some of the key issues that might cause disagreements or tensions with the union?

e) Do you have a grievance procedure at this nursing home? If so, how does it operate? How often is it used and for what purposes?

f) Have you had any recent arbitrations? If so, how many and over what issues?

g) How has the 1199 merger with other unions affected labor relations in the industry and for your home?

h) How cohesive is your bargaining unit (the nursing home owners?) Are there issues over which there is internal disagreement?

i) How will the introduction of technology in 17 homes influence the internal dynamics with the other homes?

\section{Nursing home context}

a) Is your home unique from other homes in the NYC area? If so, in what way?

b) What are some of the main employment issues you have been dealing with?

c) How have you done on your Department of Health Surveys?

\section{Nature of the intervention thus far}

a) What steps has your home taken towards the introduction of the technology?

b) What is your general impression of e-health and the work they have been doing with you on this project? 


\section{Nursing Home Field Research Protocol: Front Line Employees}

\section{Motivation and incentives for participating in the project}

a) Tell us about your work here at the home (tenure, unit, etc.)

b) Why do you think your nursing home is adopting Electronic Medical Records Keeping technology?

c) How do you and your fellow employees feel about this project?

d) How do you think the technology will benefit the nursing home and its employees?

e) Do you think there may be any negative effects of this technology for your work and the nursing home?

\section{Expectations from participating in the project and other associated outcomes}

a) How do you think this technology will affect residents - their overall condition and their care?

b) Will the technology affect staffing levels in your nursing homes? If so, in what way?

c) Do you think the technology is going to influence employee job security?

d) How will you and your unit make use of the time saved on paperwork?

e) Will this technology improve your skill level and help you in moving ahead in this industry?

\section{Labor Relations}

a) How would you describe the nature of labor relations in this industry?

b) How would you describe the nature of labor relations at the nursing home level?

c) What are some of the key issues that you and management engage over? 
d) What are some of the key issues that might cause disagreements or tensions with the management?

e) Do you have a grievance procedure at this nursing home? If so, how does it operate? How often is it used and for what purposes?

f) Have you had any recent arbitrations? If so, how man y and over what issues?

g) How has the 1199 merger with other unions affected labor relations in the industry and for your home?

h) How cohesive is your bargaining unit? Are there issues over which there is internal disagreement?

i) How will the introduction of technology in 17 homes influence the internal dynamics with the other homes?

j) Can you tell us about the recent labor dispute settled?

\section{Nursing home context}

a) Is your home unique from other homes in the NYC area? If so, in what way?

b) What are some of the main employment issues you have been dealing with?

c) How have you done on your Department of Health Surveys?

\section{Nature of the intervention thus far}

a) What steps has your home taken towards the introduction of the technology?

b) What is your general impression of e-health and the work they have been doing with you on this project?

c) What role have you played so far with e-health in the introduction of the technology? 


\section{REFERENCES}

Adendorff, D. Oct 2003. "Job Swap: Boosting Employee Morale and Resident Care." Nursing Homes: Long Term Care Management, Vol. 52, No. 10, pp. 62-66.

Anderson, R., Corazzini-Gomez, K., \& McDaniel, R. 2002. "Complexity Science and the Dynamics of Climate and Communication: Reducing Nursing Home Turnover." Academy of Management Proceedings, pp. A1.

Anderson, R., Issel, M., McDaniel, R., \& Golembiewski, R. Spring 97. "Nursing Staff Turnover in Nursing Homes: A New Look." Public Administration Quarterly, Vol. 21, No. 1, pp. 69-95.

Ashkanasy, N. M., Wilderom, C., \& Peterson, M. F. 2000. Handbook of Organizational Culture and ClimateSage,

Barley, S. 1986. "Technology as an occasion for structuring: Evidence from observations of CT scanners and the social order of radiology departments." Administrative Science Quarterly, Vol. 31, pp. 78-108.

Berger, P., \& Luckmann, T. 1966. The Social Construction of Reality. New York:Penguin,

Beyer, J., \& Trice, H. May 1991. "Cultural Leadership in Organizations." Organization Science, Vol. 2, No. 2, pp. 249-169.

Brunsson, N. 1986. "Organizing for inconsistencies: On organizational conflicts, depression, and hypocrisy as substitutes for action." Scandinavian Journal of Management Studies, Vol. 2, pp. 165-185. 
Brunsson, N. 1985. The Irrational Organization. New York:John Wiley,

Burns, L. 1993. "Trends in Hospital Physician Relationships." Health Affairs, Vol. 12, No. 3, pp. 213-223.

Carr, J.Z., Schmidt, A.M., Ford, J.K., DeShon, R.P. 2003. "Climate Perceptions Matter: A Meta-Analytic Path Analysis Relating Molar Climate, Cognitive and Affective States, and Individual Level Work Outcomes." Journal of Applied Psychology, Vol. 88, No. 4, pp. 605-619.

Chatman, J. A. 1991. "Matching people and organizations: Selection and socialisation in public accounting firms." Administrative Science Quarterly, Vol. 36, pp. $459-484$.

Cooper, C. L. 2000. The International Handbook of Culture and ClimateWiley, John and Sons, Inc.,

Davidson, M.C.G. 2003. "Does organizational climate add to service quality in hotels?" International Journal of Contemporary Hospitality Management, Vol. 15 No. 4, pp. 206-213.

Davidson, M.C.G., Manning, M., Timo, N. and Ryder, P. 2001. "The dimensions of organizational climate in four and five Australian hotels." Journal of Hospitality and Tourism Research, Vol. 25 No. 4

DeLaHunt, B. Sep 2005. "Portable documentation comes to resident care." Nursing Homes: Long Term Care Management, Vol. 54, No. 9, pp. 44-46. 
Denison, D. 1996. "What is the difference between organizational culture and organizational climate? A native's point of view on a decade of paradigm wars." Academy of Management Review, Vol. 21, No. 3, pp. 619-654.

Denison, D., \& Mishra, A. 1995. "Toward a theory of organizational culture and effectiveness." Organization Science, Vol. 6, pp. 204-223.

Deutschman, M. Fall 2005. "An Ethnographic Study of Nursing Home Culture to Define Organizational Realities of Culture Change." Journal of Health \& Human Services Administration, Vol. 28, No. 2, pp. 246-281.

Edmondson, A., Bohmer, R., \& Pisano, G. December 2001. "Disrupted Routines: Team Learning and New Technology Implementation in Hospitals." Administrative Science Quarterly, Vol. 46, No. 4, pp. 685-716.

Ekvall, G. 1987. The climate metaphor in organizational theory. In B. Bass, \& P. Drenth eds., Advances in organizational psychology. Beverly Hills, CA: Sage, pp. 177-190.

Fayol, H. 1916/1949. General and Industrial Administration. London:Sir Isaac Pitman \& Sons, Ltd.,

Fine, G. A. 1984. "Negotiated Orders and Organizational Cultures." Annual Review of Sociology, Vol. 10, No. 1, pp. 239-62.

Follett, M. P. 1926/1940. The Psychological Foundations: Constructive Conflict

Ford, E., Menachemi, N., \& Phillips, T. Jan/Feb 2006. "Predicting the Adoption of Electronic Health Records by Physicians: When Will Health Care be 
Paperless?" Journal of the American Medical Informatics Association, Vol. 13, No. 1, pp. 106-112.

Geertz, C. 1973. The Interpretation of Cultures. New York:Basic Books,

Greet, B. Mar 96. "'Mixing it up' for morale." Nursing Homes: Long Term Care Management, Vol. 45, No. 3, pp. 19.

Guion, R. 1973. A Note on Organizational Climate, Vol. 9, pp. 120-125.

Harrington, B., \& Fine, G. "Opening the "black box": Small groups and twenty-firstcentury sociology." Social Psychology Quarterly, Vol. 63, pp. 312-323.

Hofstede, G., Neuijen, B., Ohayv, D., \& Sanders, G. 1990. "Measuring organizational cultures: a qualitative and quantitative study across 20 cases." Administrative Science Quarterly, Vol. 35, pp. 286-316.

Hollinger-Smith, L. May 2003. "It Takes a Village to Retain Quality Nursing Staff." Nursing Homes: Long Term Care Management, Vol. 52, No. 5, pp. 52-54.

James, L. R., \& Jones, A. P. 1974. "Organizational climate: a review of theory and research." Psychological Bulletin, Vol. 81, pp. 1096-112.

Jehn, K., \& Mannix, E. April 2001. "The Dynamic Nature of Conflict: A Longitudinal Study of Intragroup Conflict and Group Performance." Academy of Management Journal, Vol. 44, No. 2, pp. 238-251.

Jehn, K. June 1995. "A Multimethod Examination of the Benefits and Detriments of Intragroup Conflict." Administrative Science Quarterly, Vol. 40, No. 2, pp. 256282. 
Jones, A. P., \& James, L. R. 1979. "Psychological climate: Dimensions and relationships of individual and aggregated work environment perceptions." Organizational Behavior and Human Performance, Vol. 23, pp. 201-250.

Joyce, W. F., \& Slocum, J. W. 1984. "Collective climate: agreement as a basis for defining aggregate climates in organizations." Academy of Management Journal, Vol. 27, No. 4, pp. 721-742.

Kerr, C. 1964. Labor and Management in Industrial Society. Garden City, NY:Anchor Books,

Klitch, B. Feb 2000. "Staffing: A Survey Survival Issue." Nursing Homes: Long Term Care Management, Vol. 49, No. 2, pp. 14.

Kunda, G. 1992. Engineering Culture: Control and Commitment in a High-Tech Corporation. Philadelphia:Temple University Press,

Lescoe-Long, M. October 2000. "Why They Leave: A New Approach to Staff Retention." Nursing Homes: Long Term Care Management, Vol. 49, No. 10, pp. 70 .

Lewin, K. 1951. Field Theory in Social Science. New York:Harper and Row,

Martin, J. 2002. Organizational Culture: Mapping the Terrain. Thousand Oaks, California:Sage Publications, Inc.,

Martinez-Motta, J. C., Walker, R., Stewart, T., Abrahamson, S., \& Lapinsky, S. October 2004. "Critical care procedure logging using handheld computers." Critical Care, Vol. 8, No. 5, 
Mead, G. Mind, Self, and Society. Chicago:University of Chicago Press,

Meyerson, D. 1991. "Normal" ambiguity? A glimpse of an occupational culture. Reframing organizational culture. Newbury Park, CA: Sage, pp. 131-144.

Miles, R. H. 1980. Organizational boundary roles. In C. L. Cooper, \& R. Payne eds., Current concerns in occupational stress. New York: John Wiley, pp. 61-96.

Mohr, L. 1982. Explaining Organizational Behavior. San Francisco:Jossey-Bass,

Mumby, D. K. 1988. Communication and Power in Organizations: Discourse, Ideology, and Domination. Norwood, NJ:Ablex,

Murnigahan, J. K., \& Conlon, D. E. 1991. "The dynamics of intense work groups: A study of British string quartets." Administrative Science Quarterly, Vol. 36, No. 2, pp. $165-186$.

O'Reilly, C. A., Chatman, J. A., \& Caldwell, D. F. 1991. "People and organizational culture: A profile comparison approach to assessing person-organization fit." Academy of Management Journal, Vol. 34, pp. 487-516.

Pettigrew, A. M. 1979. "On studying organizational cultures." Administrative Science Quarterly, Vol. 24, pp. 570-81.

Pondy, L., Frost, P., Morgan, G., \& Dandridge, T. 1983. Organizational Symbolism. Greenwich, CT:JAI Press,

Rahim, M. A. 2001. Managing Conflict in Organizations. Westport, CT:Quorum, 
Riley, P. 1983. "A structurationist account of political cultures." Administrative Science Quarterly, Vol. 28, pp. 414-437.

Robbins, S. P. Managing Organizational Conflict: A Non-Traditional Approach. NJ:Prentice Hall,

Rohlen, T. For Harmony and Strength: Japanese White-Collar Organization in Anthropological Perspective. Berkeley:University of California Press,

Ryder, P. A., \& Southey, G. N. August 1990. "An exploratory study of the Jones and James organisational climate scales." Asia Pacific Human Resources Management, pp. 45-52.

Sathe, V. 1985. Culture and Related Corporate Realities: Text, Cases, and Readings on Organizational Entry, Establishment, and Change. Homewood, IL:Irwin,

Schall, M. 1983. "A communication rules approach to organizational culture." Administrative Science Quarterly, pp. 557-581.

Schein, E. 1985. Organizational Culture and Leadership. San Francisco:Jossey-Bass,

Siehl, C., \& Martin, J. 1990. Organisational culture: A key to financial performance? In B. Schneider ed., Organisational climate and culture. San Francisco: JosseyBass, pp. 241-81.

Smircich, L. 1983. Organizations as shared meanings. Organizational symbolism. Greenwich, CT: pp. 55-65.

Smith, M. 2007. "Carolinas Hospital System, Personal Interview." 
Sopow, E. 2007. "The impact of culture and climate on change programs:

Distinguishing between culture and climate to change the organization." Strategic HR Review, Vol. 6, No. 2, pp. 20-23.

Stolte, J., Fine, G., \& Cook, K. 2001. "Sociological Miniaturism: Seeing the Big Through the Small in Social Psychology." Annual Review of Sociology, Vol. 27, No. 1, pp. 387-413.

Trice, H., \& Beyer, J. 1992. The Cultures of Work Organizations. Englewood Cliffs, NJ:Prentice Hall,

Van Maanen, J. 1991. The smile factory: Work at disneyland. Reframing organizational culture. Newbury Park, CA: Sage, pp. 58-76.

Van Maanen, J. 1979. "Reclaiming qualitative methods for organizational research." Administrative Science Quarterly, Vol. 24, pp. 52-6.

Van Maanen, J. 1975. "Police socialization: A longitudinal examination of job attitudes in an urban police department." Administrative Science Quarterly, Vol. 20, pp. 207-228.

Van Maanen, J. 1973. "Observations on the making of policemen." Human Organization, Vol. 32, pp. 407-417.

Verbeke, W., Volgering, M., \& Hessels, M. May 1998. "Exploring the conceptual expansion within the field of organizational behaviour: Organizational climate and organizational culture." Journal of Management Studies, Vol. 35, No. 3, pp. 303-329. 
Wallace, J., Hunt, J., \& Richards, C. 1999. "The relationship between organisational culture, organisational climate and managerial values." International Journal of Public Sector Management, Vol. 12, No. 7, pp. 548-564.

Weber, A. 1929. Theory of the Location of Industry. Chicago:Chicago University Press,

Weiss, G. March 2002. "Welcome To The (Almost) Digital Hospital." IEEE Spectrum, pp. 44-49.

Werner Institute. "http://law.creighton.edu/wernerinstitute/index.aspx?p=4."

Whyte, W. F. Summer 1967. "Models for Building and Changing Organizations." Human Organization, Vol. 26, No. 1/2, pp. 22-31.

Winkelman, W., Leonard, K., \& Rossos, P. May/June 2005. "Patient-Perceived Usefulness of Online Electronic Medical Records: Employing Grounded Theory in the Development of Information and Communication Technologies for Use by Patients Living with Chronic Illness." Journal of the American Medical Informatics Association, Vol. 12, No. 3, pp. 306-314. 